Improving Communication and Sense of Belonging in Remote Teaching

A Thesis submitted to the faculty of San Francisco State University

In partial fulfillment of

the requirements for

the Degree

Master of Science

In

Computer Science

by

Inez Wibowo

San Francisco, California

December 2021 
Copyright by

Inez Valentine Wibowo

2021 


\section{Certification of Approval}

I certify that I have read Improving Communication and Sense of Belonging in Remote Teaching by Inez Valentine Wibowo, and that in my opinion this work meets the criteria for approving a thesis submitted in partial fulfillment of the requirement for the degree Master of Science in Computer Science at San Francisco State University.

Ilmi Yoon, Ph.D.

Professor,

Thesis Committee Chair

Shasta Ihorn, Ph.D.

Professor

Anagha Kulkarni, Ph.D.

Professor 


\title{
Improving Communication and Sense of Belonging in Remote Teaching
}

\author{
Inez Valentine Wibowo \\ San Francisco, California \\ 2021
}

\begin{abstract}
When almost all campuses were locked down beginning in March 2020, due to the Covid-19 pandemic, instructors rapidly transitioned to an online-only experience. In a face-to-face classroom, students' facial expressions are apparent to instructors. Instructors can no longer see all students' faces in an online classroom as most students have cameras turned off. The studentinstructor relationship is affected as a sense of connectedness and belonging are degraded by the remote modality. In this thesis, we aim to study whether a desktop application can positively affect the student-instructor relationship. We started developing the Emotion Thermometer app in Fall 2020. We present application details, methodology, and results from a 2-3 month-long app usage in 8 Computer Science classes where 384 students enrolled. We interviewed the seven professors and ten students who volunteered to provide feedback towards the end of the semester. Quantitative data showed varying usage patterns, which is impacted by usability factors, including logging in, how active instructors prompt students to enter emotions, and their chosen modality. Although participation after the first week drops in subsequent weeks, we see an overall steady active participation level. Students actively use the text field as a suggestion box and generally provide positive comments to fellow students and their professors. Students and instructors alike found the app helpful with some room for improvement. Instructors found it cumbersome to watch the History page while sharing their screen for class materials. Students often forget they need to login, if not prompted by their instructors. On a positive note, instructors can view the minute students don't understand a topic and pinpoint that topic to clarify. Students have commented that the fact instructors are using the app changes their perception about their instructor and believe that they care about their well-being as well as academic performance. In this pandemic, we have a unique opportunity to study how an app can help reincorporate students' emotions in the classroom and bridge the communication gap created by transitioning classrooms online.
\end{abstract}




\section{KEYWORDS}

Communication, sense of belonging, online modality, remote teaching, emojis 


\section{Acknowledgements}

I would like to acknowledge my three advisors, who have not only inspired me in this study, but to continue in Computer Science and pursue higher education. This thesis would not have been possible without the help from some of the brightest, earnest, and selfless people I know: Dr. Ilmi Yoon, Dr. Anagha Kulkarni, and Dr. Shasta Ihorn. I thank you for your support and guidance throughout these last years since we started this research and since I've started my Computer Science journey. Dr. Yoon provided the idea to create the Emotion Thermometer app to improve student and teacher communication and named the application. Additionally, Dr. Yoon and Dr. Ihorn also supported and provided guidance in driving the interview questions and designing our research plan for our submission to IRB and SigCse. Dr. Kulkarni provided analytical perspective to ensure we were identifying the correct data with our questions and our research.

I would also like to acknowledge the Computer Science department at San Francisco State University (SFSU), the chair, Dr. Arno Puder, who supported all of our departments' research and efforts. And, all of the 7 professors and 384 students who were involved in this study, who were so generous with their time, feedback, and support and using this application that enabled the data we have collected to be robust. Additionally, their optimism further propelled this work to its completion. I am confident our work on the Emotion Thermometer in this study is just the beginning and we can continue to find ways to improve communication in our classrooms. 


\section{Table of Contents}

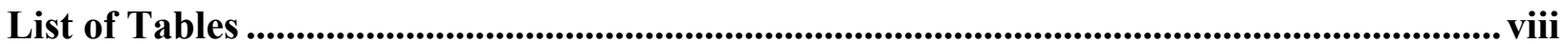

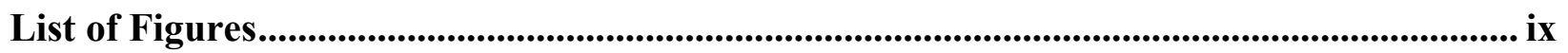

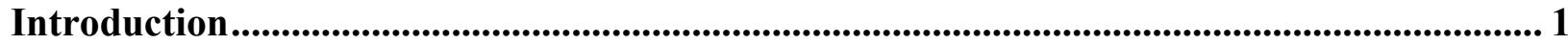

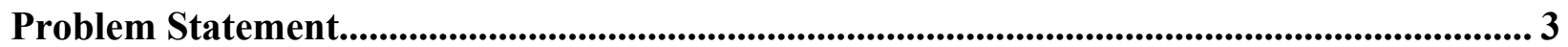

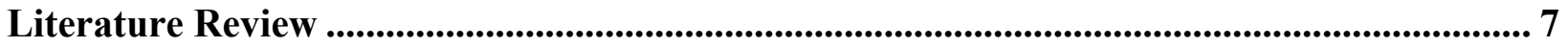

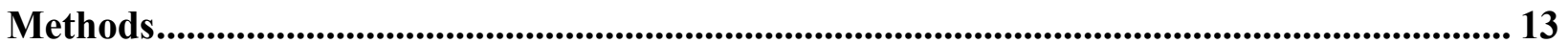

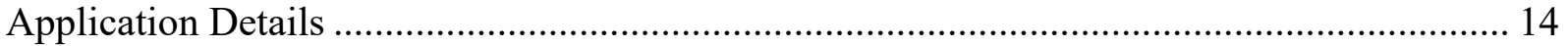

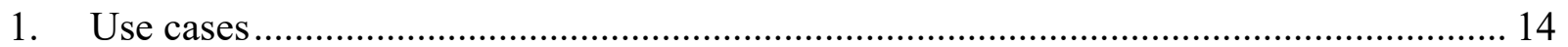

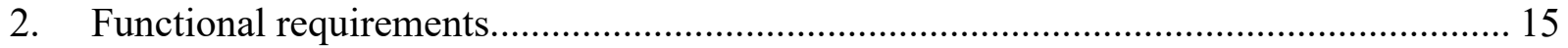

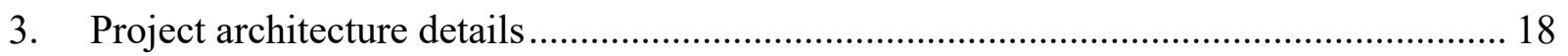

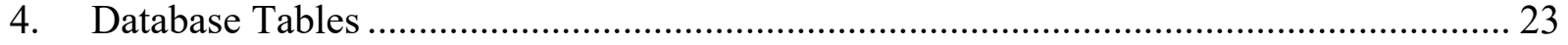

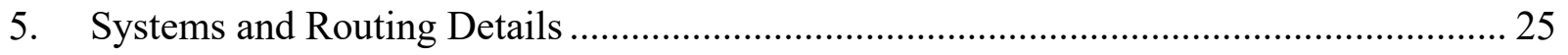

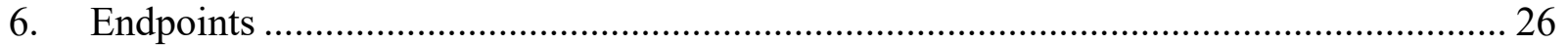

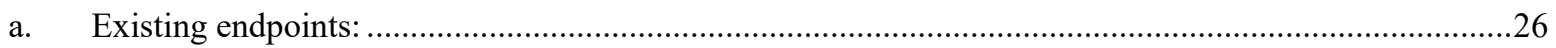

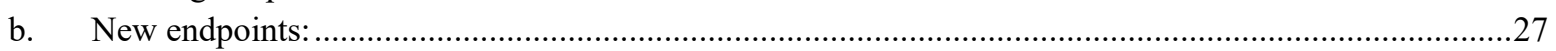

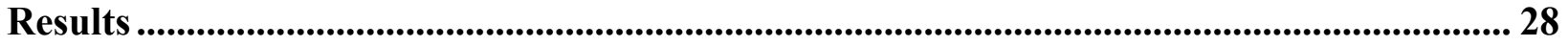

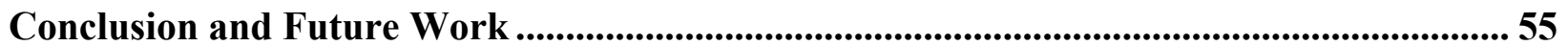

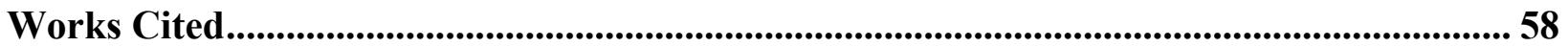




\section{List of Tables}

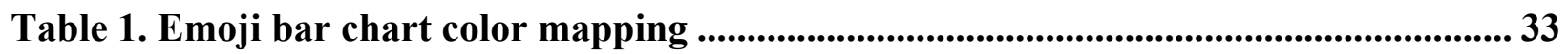

Table 2. How Positive vs Negative Comments Are Categorized ............................................ 37

Table 3. Positive vs Negative Comments posted ................................................................... 38

Table 4. Percentage table of positive, neutral, and negative comments.................................. 39

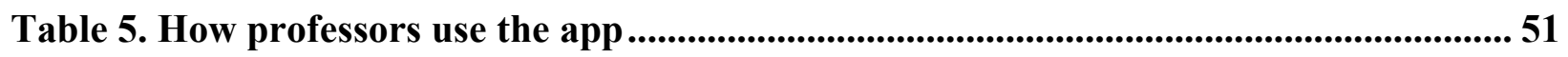




\section{List of Figures}

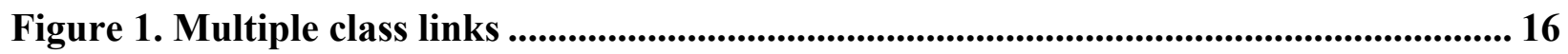

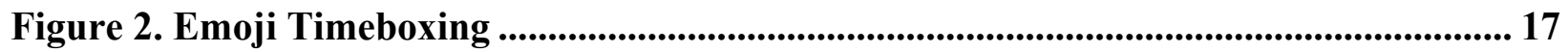

Figure 3. Restructured project files to separate................................................................... 19

Route, Controller, and Service layers separate..................................................................... 19

Figure 4. Routes restructured to separate logic and data layer ...................................... 20

Figure 5. Application routing on Route 53 ................................................................ 21

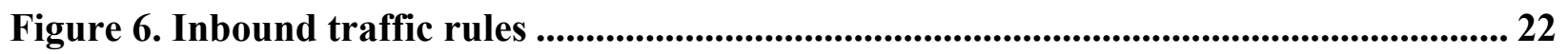

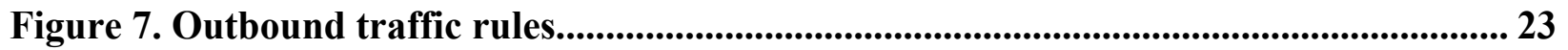

Figure 8. EmojiRecordsPerMinute database table...................................................... 24

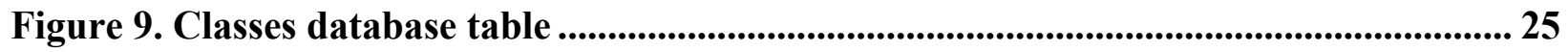

Figure 10. Emotion Thermometer Application Diagram............................................................. 26

Figure 11. Percentage of online participation level in Emotion Thermometer app ............. 29

Figure 12. Class participation level in Emotion Thermometer app..................................... 31

Figure 13. First vs Last class Online Participation ........................................................ 32

Figure 14. Emoji bar chart color mapping ................................................................. 34

Figure 15. Positive vs Negative Emotions posted ................................................................. 35

Figure 15. Positive, Negative and Neutral Comments posted .................................................. 41

Figure 16. Positive vs Negative Comments posted ....................................................................... 42

Figure 17. Percentage of comments that were anonymous ............................................... 43 


\section{Introduction}

When the lockdowns began in Spring 2020 across campuses in the United States, instructors and students quickly transitioned to classrooms in an online-only modality. Instructors now ask students for their feedback by prompting them to use the available tools by the web conferencing app of choice. Zoom, for example, provides interactive tools that include polling, choosing a hand-up emoji, or typing into the chat box as a way of giving the instructors feedback online. These online tools mimic teacher-student in-person interactions. However, none of these 3rd party tools provide emotional feedback and none of them allow teachers to retain this emotional data for further analysis. The Emotion Thermometer app we created is a tool that was specifically developed to provide emotional feedback and to collect emotional data for teachers. Students' emotional well-being is a critical component of students' willingness to return to college and general attitude towards college following the Covid-19 outbreak. Research by Simpson-Scarborough in February 10-17, 2021, interviewed 688 college-bound students and found that the environment after the outbreak has changed. College-bound students feel increasingly socially isolated and feel negatively about online and offline classrooms in general, "I feel more in the dark about colleges, and just isolated." Additionally, in another study of 266 college students in Texas conducted in April 2020, in addition to feeling worried about their own, and family's health, $86 \%$ of students felt an increased level of isolation and $82 \%$ were concerned about their academic performance. And as coping mechanisms, one-third of the participants sought support from family and friends (Son et al. 2020). Understanding this new challenging negative environment, we hypothesize that by creating a tool that aims to help students convey their feelings to their instructors, we can improve their general level of 
satisfaction with the college experience in general. We aim to identify how students used the app, what level of satisfaction do students have after using the app, and whether the teachers using the app were satisfied with it. To answer these questions, we collected data from 6 onlineonly Computer Science classes using the Emotion Thermometer app at San Francisco State University (SFSU) between the months of September through November 2021 and interviewed the 6 instructors who used the app and interviewed students in the classes who used the app and volunteered to provide feedback towards the end of the Fall 2021 semester.

One can seek and provide social support in a verbal or non-verbal manner. Thus, in an online environment, such as Zoom, we typically see social support communicated in a nonverbal way. As a non-verbal communication tool, emojis have been used for over 20 years and have been lauded as the first universal language that cuts through differences in cultures. In a 2017 research, Joanna Harn investigated whether college students use emojis as a means of gaining social support by surveying 426 Instagram posts with the tag \#collegeproblems and confirmed that college students use emojis as a way to provide each other positive social support (Harn, Ren-Whei 2017). Additionally, another researcher noted that emojis "... communicate the display of emotions people might project in face-to-face communication"(Kaye, Linda K, et al. 2017), suggesting that people can use emojis, while online, as a proxy for facial expression.

However, none of the existing research has developed a customized application to be used in an online-only classroom during the pandemic to study teacher-student relationship. We believe that we have a unique opportunity and it may have accelerated the need to integrate student wellbeing into college classrooms, as an outcome of this research during the Covid-19 pandemic. 
In the following sections, we will outline the problem we are trying to address, our research methodology, and our analyzed results. Lastly, we will provide our summary of this research and outline possible research directions for future work.

\section{Problem Statement}

Research has shown that since in-person college instruction transitioned to remote teaching since the Covid-19 outbreak in March 2020, students' opinion of universities have worsened. $63 \%$ of the college students interviewed by Simpson-Scarborough in April 2020 felt that online instruction is worse than in-person instruction. However, a year later, college-bound seniors interviewed in March 2021, when there was a mix of offline and hybrid instruction, students continue to state that the quality has degraded. $60 \%$ of the high school seniors who are taking all classes online and $56 \%$ of students taking all classes in-person have stated that the quality of their education experience has worsened. They are all less motivated and less engaged than prior to the Covid-19 outbreak. For example, US students most reported feeling "sad," followed by "disappointed," "stressed," and "upset" (Simpson-Scarborough 2020). Another research conducted during the early months of the Covid-19 pandemic, of 266 college students in Texas found $89 \%$ said they were distracted and $86 \%$ increased feelings of social isolation (Son et al. 2020). According to research of first-year Computer Science (CS) students, before the Covid19 outbreak, especially students who are first-generation and female students, there was already a lack of confidence in not completing a CS program (LeBlanc 2018). Thus, all students' emotional well-being, especially first-generation and underrepresented students in CS, have been 
impacted negatively by the pandemic. Feelings of stress, and the perception of lacking support in the classroom, negatively affect a student's sense of belonging. And, research has shown that sense of belonging is tied to academic performance, especially in introductory computer science courses, as it affects their grades and pass rates (Kaye 2017).

Understanding how students experience these negative feelings in the Covid-19 environment, we wanted to provide students with additional means of coping by expressing emotions in the classroom in a non-verbal manner so that they can feel less stressed and more supported. In an online classroom, apart from the professor, fellow students hear little from each other. And, as most students have their cameras off, not seeing any of your classmates can increase the feelings of loneliness. This online environment also impacts professors because only a handful of students speak up, professors only receive a small subset of feedback from their students. Thus, we developed the Emotion Thermometer app to provide all students with a way to communicate their emotions with fellow students and their instructors. We hypothesize that by providing a way to communicate their emotions, students will feel more connected to their class, professors will gain helpful feedback, and students will feel more positive with the class experience. It has been shown that non-verbal communication can make students feel more comfortable with their professors and their level of comfort and their sense of confidence in the subject matter are strongly related (York 2014).

The Emotion Thermometer application is mainly a desktop application that is mobile responsive. And, to ensure instructor's and student's privacy, the link to each class is unique and students will be required to log in. Once logged in, students can anonymize their responses by toggling the "Anonymous" button. The decision to use emoji to communicate emotions is based 
on our desire to make communicating in an online classroom more fun, easier than typing, while staying contextually relevant. And past research found that only $7 \%$ of the message is communicated verbally while $93 \%$ was communicated through facial cues (Archer \& Akert, 1977; Mehrabian, 1972). If most messages are communicated through facial cues, then, in an online-only classroom, the professors are potentially losing $93 \%$ of the message communicated by students. In order to support the communication of non-verbal messages, particularly facial cues, we theorize that we can use emojis as a proxy. Research have shown that emojis can be used as a proxy for emotions. In a 2017 research, Joanna Harn surveyed 426 Instagram posts and half confirmed to use emojis as sources of positive social support. The posted topics range from, "schoolwork, self-expression, and physical and mental health..." (Harn 2017). Kaye et al. noted that emojis "... communicate the display of emotions people might project in face-to-face communication" (Kaye 2017), which confirms that emojis are used in computer-mediated communications as a proxy for emotions.

Additionally, because this application is used in a classroom setting, we can further label emojis with students' level of understanding. When the students choose a frustrated emoji 2aic), he/she was indicating not only that they are frustrated but also indicating that "I completely don't understand." On the color-coded histogram History chart, the professor can see whether the class is following the topic or not as they are teaching and could slow or continue with the lecture as more students get it. See Figure 2. Before developing the Emotion Thermometer app, we also conducted an anecdotal survey of students on which emoji images, and which labels might be the most appropriate to use for the app and so the five emojis were chosen. 
In order to encourage honest feedback, we chose to make students emoji selections anonymous. This feature has its pros and cons. Students can be anonymous and feel more candid about posting a negative emoji. However, professors are not able to personally address the student who posted that emoji. We hope that sense of connection and support can occur indirectly. For example, upon seeing the "I'm completely lost" or "I don't understand" emojis, the instructor would acknowledge the existence of these emojis in class and address them verbally. Or students who see the "I don't understand" emojis from their fellow students would feel less lonely and more encouraged to post truthfully. We did, however, provide students the ability to provide a comment without being anonymous, by entering their own comments in a free text field, which will allow the professor to call on the student and provide feedback directly.

Another limitation of the app is that we have created the application with authentication. Students and professors are required to login or register to set up an account. However, in practice, it does hinder from a more spontaneous and anonymous use of the app. We would recommend that future iterations of the app would allow students to access the Emotion Thermometer app by a unique link without the need for authentication. 


\section{Literature Review}

Here, I cover six literature pieces that have conducted empirical research to find a relationship between students' emotions, the role of emojis, and their relevance to academic performance. Our research is interested in how an application using emojis can improve teacherstudent communication in a remote teaching Computer Science higher education environment. However, in the literature below, you'll find studies that include the same elements, i.e., emojis or higher education. Still, none of the literature will consist of all the parts involved in our research: custom emoji app, online-only class, higher education, and Computer Science.

Literature 1. Harn, R. J. The Visual Language of Emojis: A Study on College Students' Social Support Communication in Online Social Networks. (2017).

In one of the first studies analyzing college students' attitudes toward emojis, Harn's research in 2017 found that smiley emojis are most often used to accompany posts containing emotional support in an online environment. Furthermore, since visual cues like facial expressions are absent online, smiley emojis are more frequently used to communicate the emotion people might project in face-to-face communication (Kaye et al., 2016). From analyzing 1180 Instagram posts, filtered by \#collegeproblems, Harn found that college students express their emotions using emojis to gain and receive social support. For example, on issues related to college adjustments, "...such as academic challenges, homesickness, long-distance relationships, and financial problems" (Harn, 2017).

Even though the data collected in this research was out-of-class and on a 3rd party platform, Instagram, we can see an example of the use of emojis in college-level discourse. 
Furthermore, Harn found college-level students use emojis to convey social support. In Harn's research positive emojis were most often used and they had attributed it to the availability of positive emojis versus negative emojis. However, the ratio of positive to negative emojis provided in our research is equal. Two emojis reflect positive emotions "I'm getting it" and "I completely understand" and two emojis reflect negative emotions, "I think I'm lost" and "I completely don't understand." We found $99 \%$ of the emojis chosen are positive ones. On average, in a class of 40-50 students, we will find one or zero negative emojis per minute. Perhaps, when students are feeling a negative emotion, they may feel it more appropriate to use the free text as it is a more serious topic.

Literature 2. Son, C., Hegde, S., Smith, A., Wang, X, \& Sasangohar, F. Effects of COVID-19 on College Students' Mental Health in the United States: Interview Survey Study. 2020

To help us understand how the Covid-19 pandemic has affected the emotional wellbeing of students, we looked at a research paper by Son et al. in 2020. The team conducted a mixed methods research with 195 students at a university system in Texas, which closed their campuses and has had virtual classes since March 2020. Of the 195 students, $71 \%$ indicated increased stress and anxiety due to the COVID-19 outbreak, 91\% were concerned for their loved ones, $89 \%$ found it difficult to concentrate, $86 \%$ found disruption in sleeping patterns, and $86 \%$ had increased concerns about academic performance. To cope with stress and anxiety, the researchers noted that participants sought support from others.

This research helped us become more aware of students' negative perceptions towards academics before using the Emotion Thermometer app. Additionally, Son et al.'s research also 
points to how participants cope with negative emotions by seeking support from others. This fact affirms our choices to use emojis, which college students can use to gain and receive social support (Harn 2017).

Literature 3. Emma R. Wester, Lisa L. Walsh, Sandra Arango-Caro, and Kristine L. Callis-Duehl. Student Engagement Declines in STEM Undergraduates during COVID-19-Driven Remote Learning. 2021

Keyword: in-class participation, sense of belonging, self-efficacy

The researchers surveyed 23 different educational institutions of undergraduate science students and hypothesized that student engagement would decline under the stressors of the pandemic. To measure effectiveness in learning, they leveraged Trujillo's and Tanner's (Trujillo \& Tanner 2014) three constructs of effective learning. The three constructs are self-efficacy -how a person acquires beliefs about their ability to do something, sense of belonging -- acquiring a feeling of being part of a community, and science identity -- seeing oneself as a scientist. The results did not show an overall shift in student self-efficacy or sense of belonging pre- and postCovid outbreak. However, they did see less student participation in class and increased student visitation to the professor's office. The researchers hypothesized that the decreased in-class participation may be due to less interest or less opportunity to engage in active learning in class.

This research emphasizes the reasoning behind less participation in classrooms that are out of our control. We have observed that student participation in the app decreased $40 \%-50 \%$ since the first time the application is used. This could be because teachers or students are not triggered to provide input to the Emotion Thermometer app regularly but also it could be because of the negative environment we are in during the pandemic. Thus, it may be instructive to try $\mathrm{t}$ 
increase participation levels but also consider external factors, such as how the Covid-19 pandemic environment might suppress participation levels despite classroom efforts.

Literature 4. Sax, Linda J.; Blaney, Jennifer M.; Lehman, Kathleen J.; Rodriguez, Sarah L.; George, Kari L.; and Zavala, Christina, "Sense of Belonging in Computing: The Role of Introductory Courses for Women and Underrepresented Minority Students" (2018).

Another research discusses the connection between sense of belonging and the academic success of college students, especially for underrepresented groups. Particularly, this research looked at Computer Science classrooms and introductory computing courses. Sense of belonging is defined as the feeling a student has of how they are connected. It is defined in this research report as, "Student's perceptions of campus supports, experiences of feeling cared about, and connectedness with faculty, staff, and peers." After testing with students in 15 universities across the United States, 11944 students completed the pre-test survey and 1355 completed the post-test survey. Sense of belonging was measured by respondent's agreement with statements like "I feel like I 'belong' in computing" or "I feel like an outsider in the computing community." The results pointed to students feeling more sense of belonging when they feel supported by their department and their peers in computing. The research also investigated how sense of belonging evolved with different demographics and noted that women in computing experienced declines in their sense of belonging over time.

This research affirms the relationship between sense of belonging and students' academic success in Computer Science classes. In our research, we won't focus on the sense of belonging directly and its correlation with academic success, but whether students' experiences with the application increased their level of satisfaction and hence whether it affected their sense 
of belonging. In future research, we suggest further study can be done to study the correlation between sense of belonging from students to their academic success in class.

Literature 5. DeAndrea, D.C., et al., Serious social media: On the use of social media for improving students' adjustment to college. Internet and Higher Education (2011).

Research by DeAndrea et al. in 2011, tested how a social media website they created to welcome students to the university can change students' perception about their campus experience related to their sense of self-efficacy, which is a person's sense that they can enact successful behavior and that it will be effective. 1616 students completed the post-test surveys and 265 completed pre-test surveys. The results showed that students with self-reported website activity predicted self-efficacy. Additionally, the researchers posit that students who believed they had an online community to gain information from their peers were key in helping students believe that they could get help when needed.

While the Emotion Thermometer is not a social media site or an online billboard where students can post questions or answers, some students have used the text field in the app to provide emotional support and post questions. For example, one student posted "Let's get CONFIDENT," and another student posted a specific question about the topic discussed. With this research paper and our results, we gain the perspective that maybe in future iterations of the Emotion Thermometer app, it would be helpful to expand the Emotion Thermometer app, or provide a link to the Emotion Thermometer app from the SFSU department site to welcome students to the university and they could download the SFSU app that includes the Emotion Thermometer app, with its emojis, free text-field, and other features. If the free text-field were 
designed so that students can not only ask the professors but also ask other students to help each other, for example it could help increase students' sense of self-efficacy.

Literature 6. Pourmand, A., Quan, T., Amini, S. B., \& Sikka, N. Can Emoji assess patients' mood and emotion in the emergency department? An emoji-based study. (2020) Research by A. Pourmand et al in 2020 made use of emojis in an in-person setting to assist communication between patient and caregiver. The research reported that by using the application, patients were able to increase their mood by a .53 mean after comparing the emojis pre and post arrival to the emergency room. 348 participants, age $18-81$, upon arrival to the emergency room, were asked to choose between ten different emojis, see Figure 2. Every 30 minutes the patients were asked to identify their emoji and changes were recorded. The researchers found that $32 \%$ did not change their emotions, $30 \%$ improved their moods, and 25\% had worsening moods.

From this research we learn that emojis can be useful in both online and offline environments. Additionally, the patients were asked to submit their emojis every 30 minutes. Although the Emotion Thermometer app automatically submits students' emoji every minute, we could test whether a periodic reminder can help students provide a more accurate reading of their emotions. Some students may forget to change their emoji selection to match their state of understanding if not prompted by their instructors.

However, none of the existing research has studied the use of emojis in an online-only classroom during a pandemic. We believe we will have results that could be the beginning of future research into more applications of emojis to affect a sense of belonging in future Computer Science classrooms. 


\section{Methods}

We used a mixed-method research and collected quantitative data using the application in 6 Computer Science classrooms between September-October 2021 and collected qualitative data from online interview sessions with individual instructors and students. All questions and methods of research were previously submitted and approved by the Institutional Review Board (IRB) at San Francisco State University. Before the class starts, instructors and students would

be provided with their Emotion Thermometer accounts login and password to minimize the time lost in students and instructors registering during class time. When the class begins to use the Emotion Thermometer app for the first time, the researcher attends each class, introduces the application, and provides login details for the students.

Students can choose one of the five emojis by selecting the radio button that closely matches their current emotion. When student's login, the default selected emoji is the "Neutral" emoji. Every minute, the application will submit whatever is the last emoji selected by the student within that minute. Each emoji is labeled with a statement of a student's level of understanding, from "I completely don't understand" to an increasing level of understanding, "I completely understand," see Figure 1. Emojis will reset after five minutes back to "Neutral". This reset mechanism can help trigger students to periodically update their emotion so that it can be as close to what they're feeling.

In the History chart, we use a color-coded bar chart by CanvasJs that both instructor and students can view. "I completely don't understand," is Red, "I think I'm lost" is Orange, "Neutral" is Yellow, "I think I'm getting it" is Blue, and "I completely understand" is Green. When the application detects the students are logged in, or that their session is still active, but 
they are not actively on the Emoji sharing page, then we see a Light Grey bar for that student. Dark Grey colors represent the count of students who are registered for the class but did not log into the Emotion Thermometer app.

As we approach the end of the class, in November, we interviewed 7 students and 6 professors, individually, to collect impressions of the use of the app in class.

\section{Application Details}

The Emotion Thermometer was initially developed in Fall 2020 by Raya Farshad under the supervision of Dr Ilmi Yoon. I continued to develop the app starting Spring 2021 through Fall 2021. The overall systems architecture of the Application has been modified for ease of maintenance for both developer and user feedback.

\section{Use cases}

We have added additional use cases to previously existing use cases from "Emotion Thermometer App" (Farshad 2020)

a. Use Case \#6: Andy is an instructor who is teaching several classes. He wants to be able to see a list of classes he previously created.

b. Use Case \#7: Josie is an instructor who is interested in students who are online but did not participate. She wants to be able to view the online not participated counts long with other who are online and not participated in the history chart.

c. Use case \#8: Gina is an instructor who will use the app several times throughout the semester. She wants to be able to view historical charts and compare them. 
d. Use case \#9: Julie is an instructor who would like to use the app to prompt students for immediate response. She wants to be able to view responses faster than 1 minute.

e. Use case \#10: George is a student who forgot the class id. He wants to be able to look up the class link to login, so that he can participate with the Emotion Thermometer app.

f. Use case \#11: Jon forgot his existing password and needs to reset the password. He would like to simply go to the app and reset his existing password.

g. Use case \#12: Susie is registered to several classes that use the Emotion Thermometer app. She does not want to register to each class and wants to simply sign up without registering again.

\section{Functional requirements}

We have added additional use cases to previously existing use cases from "Emotion Thermometer App" (Farshad 2020)

a. Requirement \#10: Teachers shall be able to create multiple links 


\section{Figure 1. Multiple class links}

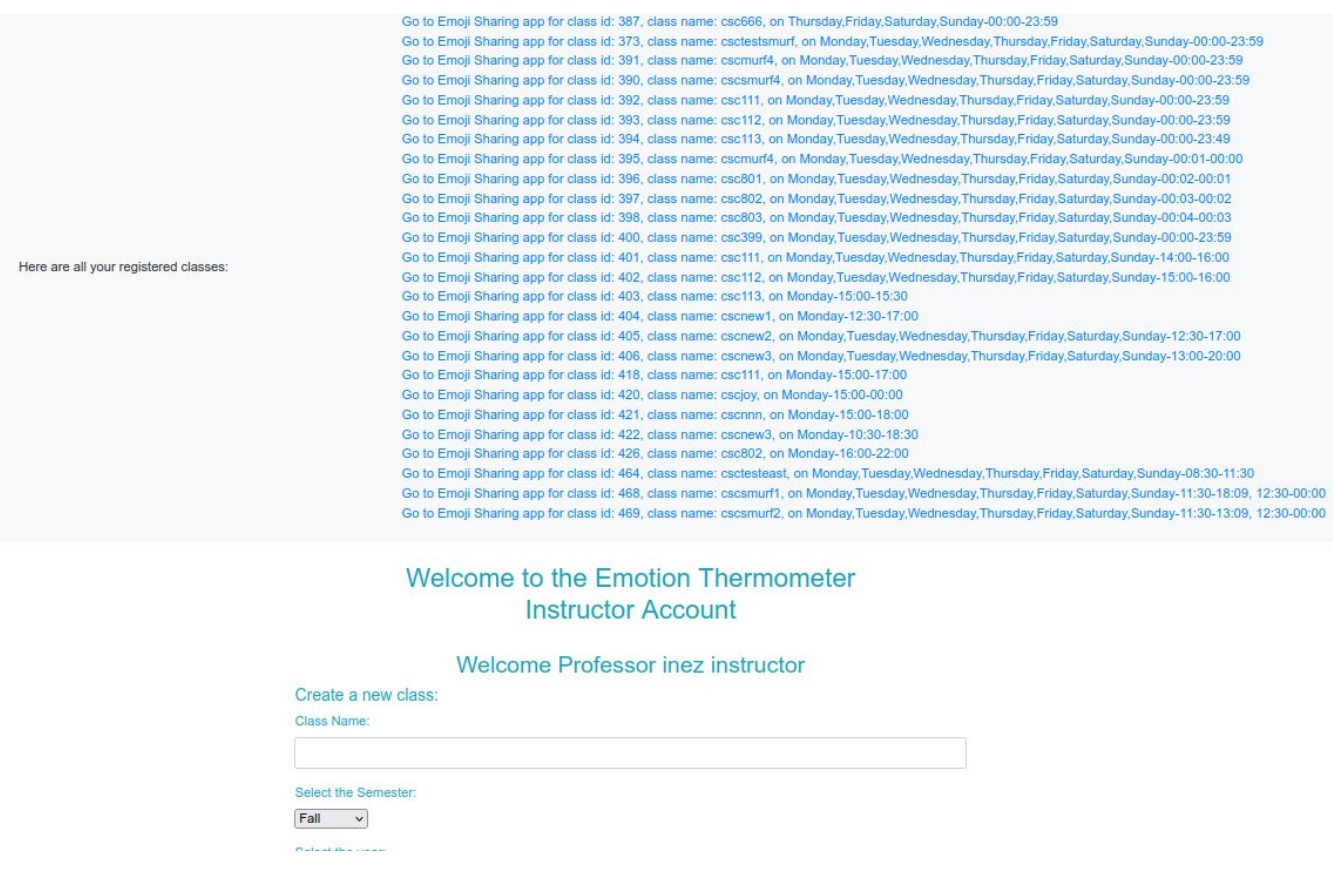

Figure 1. Multiple class links are shown on the Instructor page after instructors create new classes

b. Requirement \#11: When a teacher is logged in to Emoji page their emoji choices are not recorded

c. Requirement \#12: When students log into the Emoji page outside of class time, the emoji choices will not be recorded 


\section{Figure 2. Emoji Timeboxing}

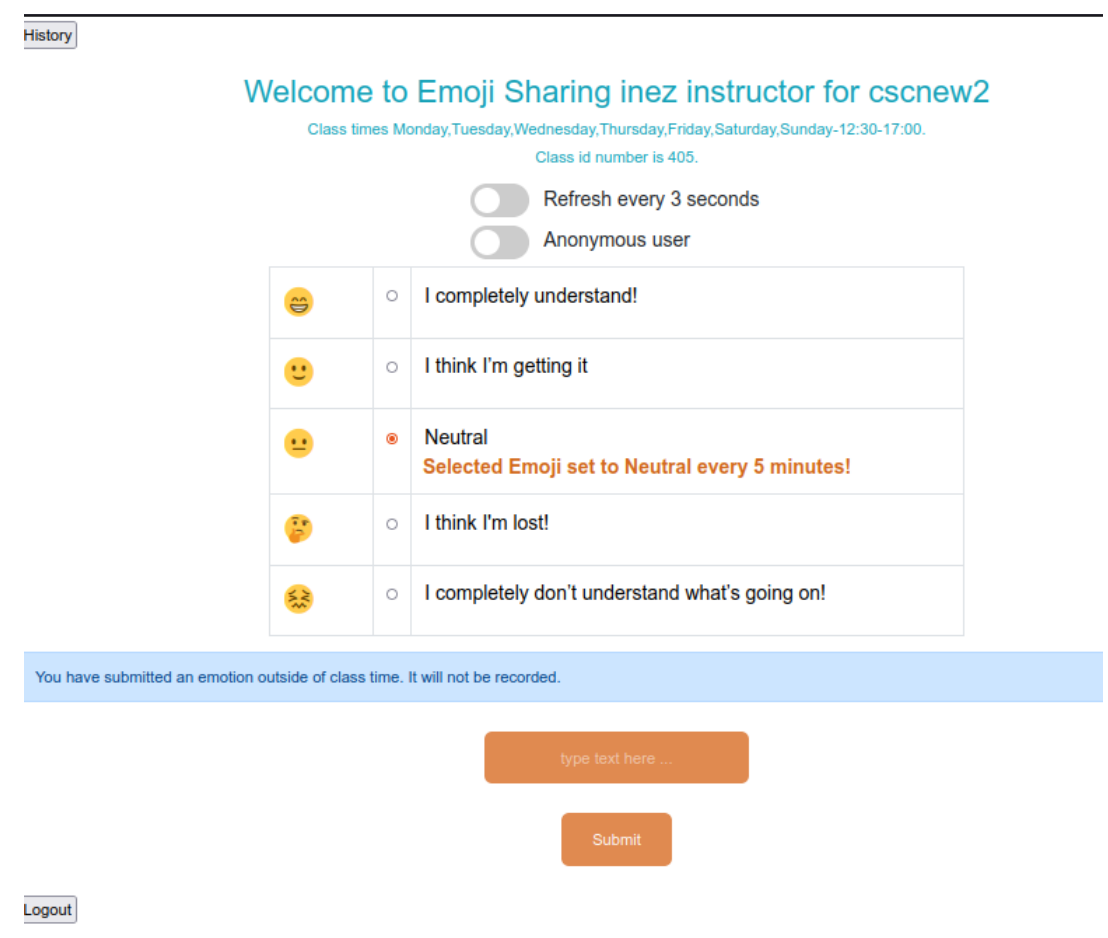

Figure 2. A banner message notifying the user that they have submitted an emotion outside of class time and it won't be recorded

d. Requirement \#13: When the History button on the Emoji page is selected, it opens in a new tab to allow the Emoji page to remain open

e. Requirement \#14: When historical page links are selected, each link opens on a new page.

f. Requirement \#15: Only teachers can view the Refresh every 3 second slider on the Emoji page. 
g. Requirement \#16: When the Teachers Refresh every 3 second slider on the Emoji page is active, all online students' emoji pages will submit emojis every 3 seconds.

h. Requirement \#17: When the Refresh every 3 second slider is active, when the History button is selected, the History page will refresh every 3 seconds.

\section{Project architecture details}

a. Folder Structure: The repository has been restructured to follow best practices where logic has been separated into Controller, Service layer and Routes. We restructured to allow easily adding new features and reuse existing functionality. The Routes triggers the Controller, which then calls the Service layer, that interfaces with the database. We have a separate folder for scripts, as well as for configuration. 
Figure 3. Restructured project files to separate

Route, Controller, and Service layers separate

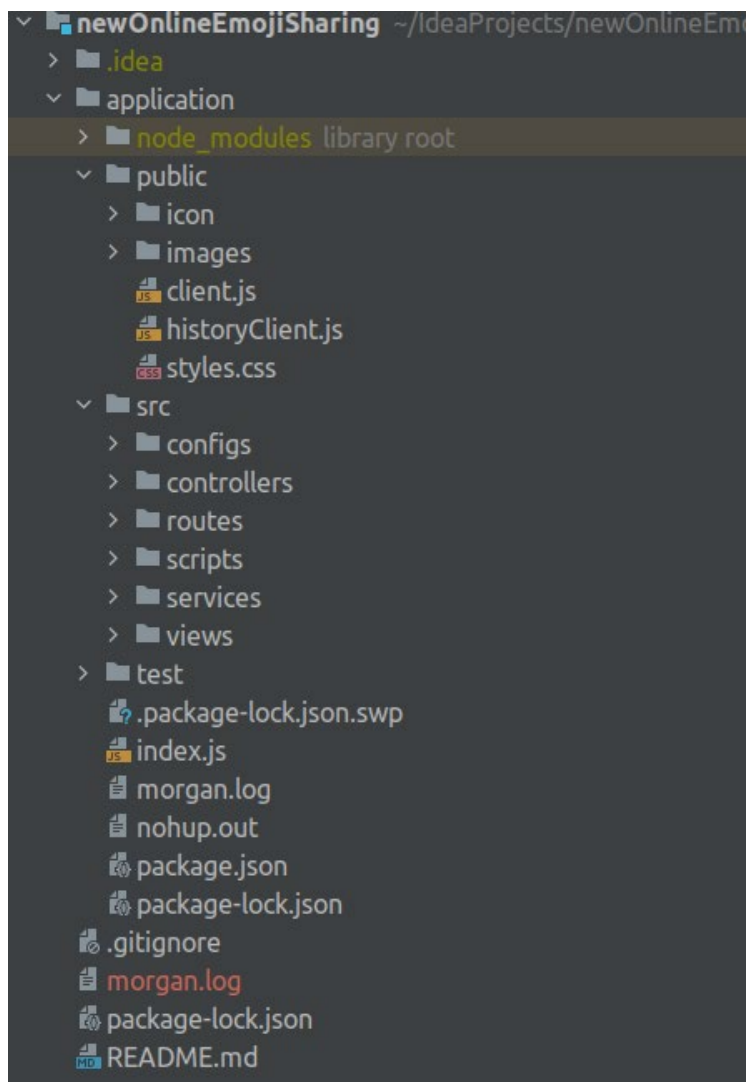

Figure 3. Project folder restructured to group controllers, views, services, separately

b. Routes: Routes have been restructured so that we can more easily identify subsequent calls and separate router, controller, service from database access. 
Figure 4. Routes restructured to separate logic and data layer

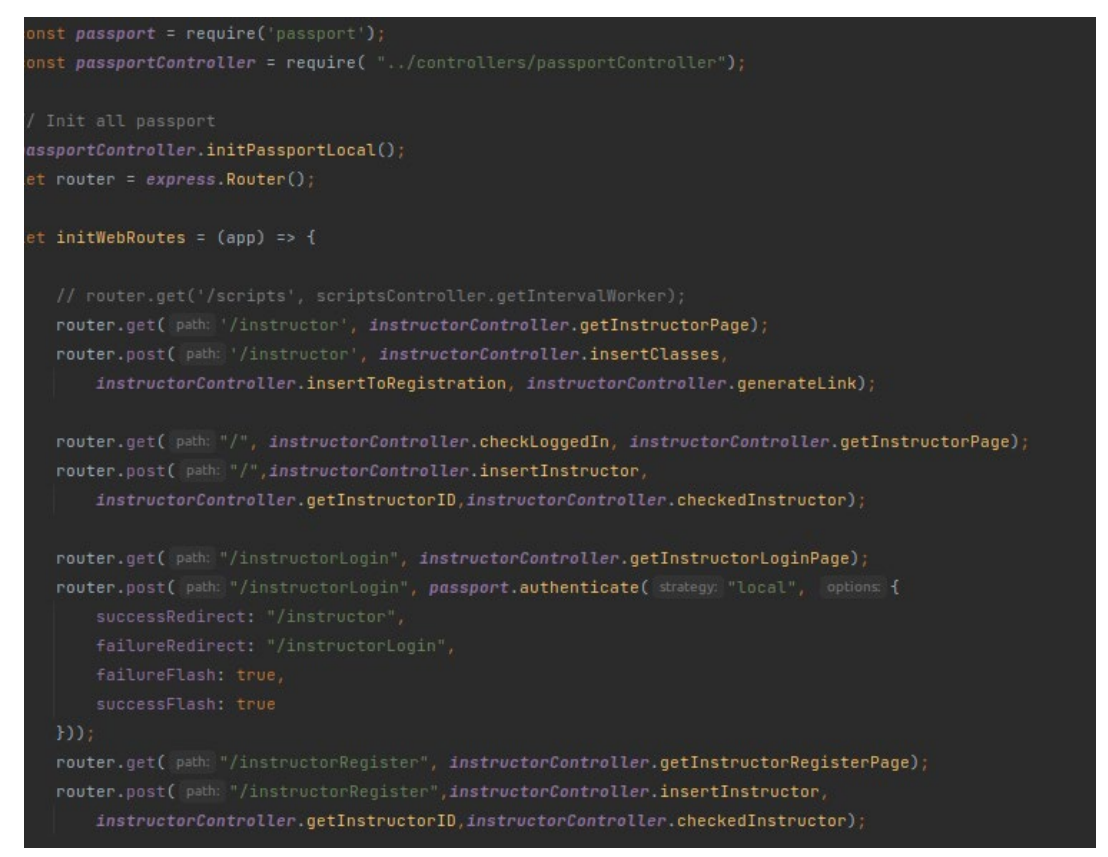

Figure 4. Route file calls Controllers, that calls Service layer, and then accesses Database layer

c. Sync/Async: We have modified all async calls to only use async when it can run parallel to another function. Functions that are dependent on another function completing are no longer async.

d. Operating System: Ubuntu Server 18.04 LTS amd64, Instance type: t2.micro

e. Networking

i. Public DNS (IPv4): ec2-54-215-121-49.us-west-

1.compute.amazonaws.com

ii. Public IP address: 54.215.121.49

iii. Elastic IP address: 54.215.121.49 
iv. AWS Route 53 connects web requests, to emotionthermometer.online to out Ubuntu application on EC2

Figure 5. Application routing on Route 53

\begin{tabular}{|c|c|c|c|c|c|}
\hline Record name & $\nabla$ & T... $\nabla$ & Rou... $\nabla$ & Di... $\mathbf{\nabla}$ & Value/Route traffic to \\
\hline emotionthermometer.online & & A & Simple & - & www.emotionthermometer.online. \\
\hline emotionthermometer.online & & NS & Simple & - & $\begin{array}{l}\text { ns-279.awsdns-34.com. } \\
\text { ns-1919.awsdns-47.co.uk. } \\
\text { ns-811.awsdns-37.net. } \\
\text { ns-1382.awsdns-44.org. }\end{array}$ \\
\hline emotionthermometer.online & & SOA & Simple & - & ns-279.awsdns-34.com. awsdns-hostmaster.amazon.com \\
\hline www.emotionthermometer.online & & A & Simple & - & 54.215.121.49 \\
\hline
\end{tabular}

Figure 5. Emotion Thermometer app routing on Amazon Route 53

v. DNS Godaddy.com is where our Domain name, emotionthermometer.online, is registered.

f. Security

i. Inbound Rules 
Figure 6. Inbound traffic rules

\begin{tabular}{|c|c|c|c|c|c|c|c|}
\hline \multicolumn{4}{|l|}{ Inbound rules (10) } & & Manage tags & \multicolumn{2}{|c|}{ Edit inbound rules } \\
\hline \multicolumn{6}{|c|}{ Q Filter security group rules } & & $\langle 1\rangle$ \\
\hline Security group rule... $\nabla$ & IP version & $\nabla$ & Type & $\nabla$ & Protocol & $\nabla$ & Port range \\
\hline sgr-043edfd5283f55b15 & IPv4 & & HTTPS & & TCP & & 443 \\
\hline sgr-0b0cfaf62a81db273 & IPv4 & & SSH & & TCP & & 22 \\
\hline sgr-0efb230ecad013f19 & IPv6 & & SSH & & TCP & & 22 \\
\hline sgr-01f09748c7ef3d216 & IPv4 & & Custom TCP & & TCP & & 4000 \\
\hline sgr-03e894e2b4b0ed99f & IPv4 & & MYSQL/Aurora & & TCP & & 3306 \\
\hline sgr-0424278a 14352 fbe 3 & IPv6 & & MYSQL/Aurora & & TCP & & 3306 \\
\hline sgr-09a398873317e1e... & IPv6 & & Custom TCP & & TCP & & 4000 \\
\hline sgr-0de40078e13c6b5... & IPv4 & & HTTP & & TCP & & 80 \\
\hline sgr-04bc1bd7cd209ec86 & IPv6 & & HTTP & & TCP & & 80 \\
\hline sgr-0cf7d49699d8fc81d & IPv6 & & HTTPS & & TCP & & 443 \\
\hline
\end{tabular}

Figure 6. Inbound traffic to the Emotion Thermometer app 
ii. Outbound Rules

Figure 7. Outbound traffic rules

\begin{tabular}{lllllll} 
Type & $\nabla$ & Protocol & $\nabla$ & Port range & $\nabla$ & Destination \\
\hline All traffic & All & All & $0.0 .0 .0 / 0$
\end{tabular}

Figure 7. Emotion Thermometer app outbound traffic rules

g. Runtime environment:

i. Node: v14.15.4

ii. Npm: v6.14.10

h. Database:

i. MySQL: Ver 14.14 Distrib 5.7.36

ii. Username: publicadmin, password: 1600holloway

\section{Database Tables}

a. EmojiRecordPerMinute table and PostedEmojiRecord table hold the same emoji data with minor differences. PostedEmojiRecord table mainly provides the text that the user enters the text field. Both tables can be combined. 
Figure 8. EmojiRecordsPerMinute database table

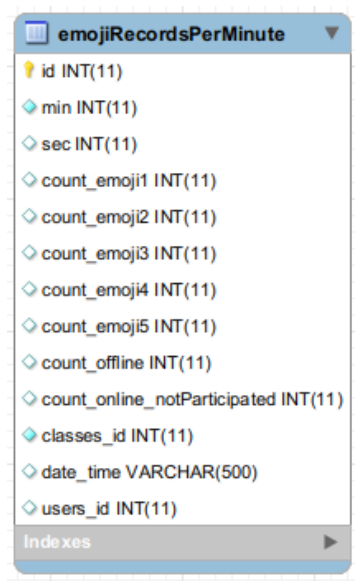

Figure 8. Three additional columns "count_offline", "minute” and "users_id" was added to EmojiRecordsPerMinute table

i. The column 'count_offline' has been added to the EmojiRecordPerMinute to help us track how many students were offline at each minute.

ii. The column 'minute' has been added to the EmojiRecordsPerMinute to help us ensure that if the same user submits several emojis, only the last one is counted.

iii. The 'users_id' column has been added to ensure we only count emojis from the same user once in 1 minute but count all emojis by different users. 
b. Classes table has remained the same but class_name and datetime has been expanded to include a longer name.

\section{Figure 9. Classes database table}

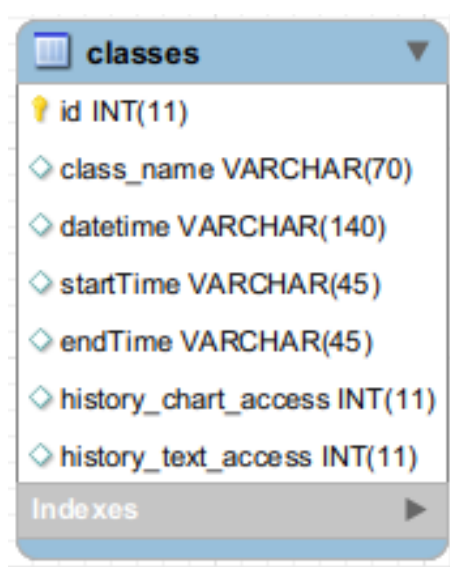

Figure 9. Classes table with expanded "class_name" and "datetime" columns

c. EmojiRecordPerMinute table and PostedEmojiRecord table hold the same emoji data with minor differences. PostedEmojiRecord table mainly provides the text that the user enters the text field. Both tables can be combined.

d. Relationships between tables in the current app has not changed since Raya Farshad set up the database in 2020 (Farshad 2020)

\section{Systems and Routing Details}

a. Amazon AWS server: The EC2 instance is an Ubuntu machine, which includes MySQL as the database and uses NodeJS server and Express Framework. We have 
added a router service provided by Amazon, Route 53, to enable the use of load balancing.

Figure 10. Emotion Thermometer Application Diagram

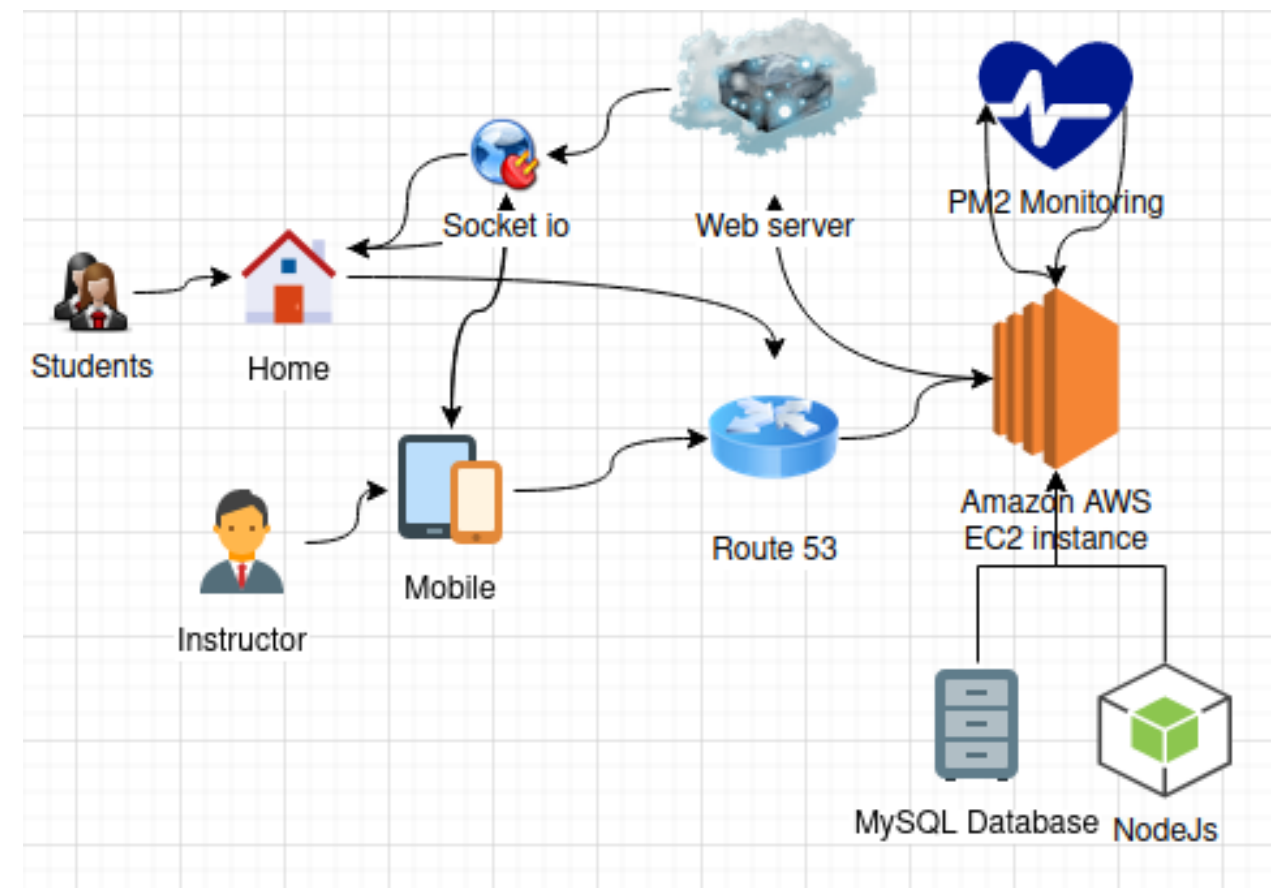

Figure 10. Emotion Thermometer application architecture diagram shows how the app uses Route 53 to connect to the EC2 instance AWS Ubuntu through the Domain name emotionthermometer.online. The application running on EC2 instance is monitored by PM2. The Socket io monitors users who are logged and logged out.

b. Monitoring: We have used PM2 to allow for constant monitoring of CPU usage, logging, and automatic restart should the application crash.

c. Sockets: We use Socket.io to send data from the client to the server of who are online participating and not participating. We also use sockets to send the status of the "Refresh every 3 seconds" slider to all the connected users.

\section{Endpoints}

\section{a. Existing endpoints:}


i. /home, /generateLink, /EmojiSharing, /sendEmoji

ii. /login, /register, /logout for students

iii. /signUp, allow students who have registered for other classes, to bypass registration and add another class

\section{b. New endpoints:}

i. /

1. GET: redirect to /instructor

ii. /instructorRegister

1. GET: load page to add instructor

2. POST: insert new instructor into the database

iii. /instructorLogin

1. GET: load page for instructor to login

2. POST: insert new instructor into the database

a. Successful: redirect to /instructor

b. Failure: redirect to/instructorLogin

iv. /instructorLogout, allow Instructors to log out from instructor account

v. /getClassLink

1. GET: load page to look up class link by the id

2. POST: list class links that match class ids entered

vi. /forget-password, allow students to reset password

1. GET: load page to enter email

2. POST: generate unique $10 \mathrm{~min}$ link to reset password page 
vii. /reset-password/:id/:token, reset unique tokens to reset password

1. GET: load for students to reset password

2. POST: enter new password into the database

viii. /history

\section{Results}

Six professors at San Francisco State University (SFSU) used the Emotion Thermometer app in 8 classes and 384 students. There are 30-60 students registered in each class. Three classes were Computer Science classes for non-Computer Science majors, and the remaining five classes were for Computer Science majors. Classes started to use the application in September - October 2021 until the end of November 2021. The Emotion Thermometer app was introduced in 7 classes and actively used in 6 classes.

To answer our first research question: "How do students use the Emoji app?", we will look at quantitative data gathered by the application and later qualitative data from feedback sessions with students. In all the classes, the number of students' who were logged into the application at the beginning and at the end of the class does not differentiate widely. This means that once students are logged in at the beginning of the class they appear to remain logged in until the end of the class. Online participation decreased when comparing online participation of subsequent classes. We saw an overall decline online participant, except for the online participation in Class 5 which increased $6 \%$ from $21.36 \%$ to $27.56 \%$. However, on average, when first to last class average online participation is compared, the average drop in online 
participation is $56.32 \%$. When we look at all the classes, we can see that the average

participation is $18.15 \%$, or $\sim 8$ students per class, in which $30-60$ students were enrolled. We can look at Figure 11 to see the online participation recorded for each class, which averages to $18.15 \%$.

Figure 11. Percentage of online participation level in Emotion Thermometer app

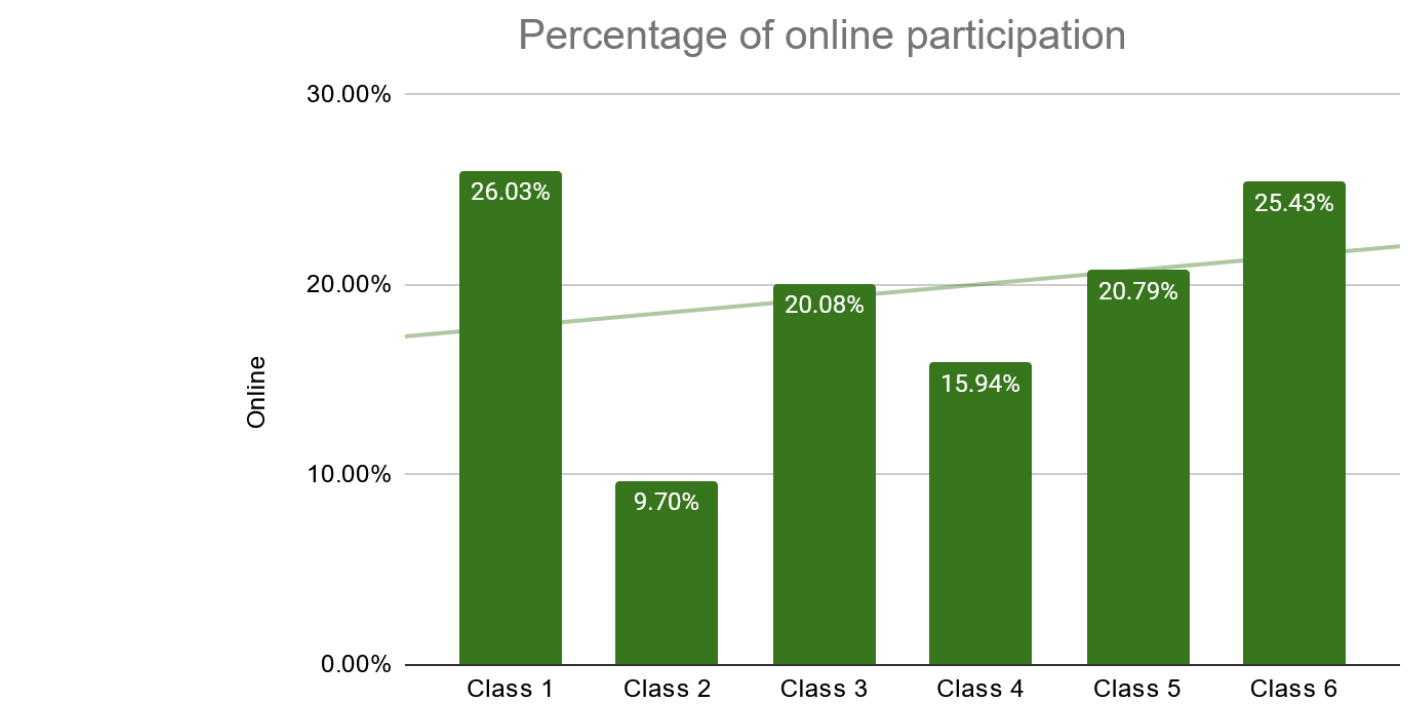

Figure 11. Class participation levels in percentages of those Online from the first class to the last class that introduced to the Emotion Thermometer app

Next, we wanted to compare student participation from class to class. Figure 12 shows the class participation levels of each class where the Emotion Thermometer was used. Figure 13 shows the class participation level of just the first and last class online participation to better understand the cumulative drop off on average of all classes. The proportion of students who participated in the first class in which the Emotion Thermometer app was introduced had the 
highest participation level. We see a drop but steady level of participation in subsequent classes. This could mean that after the initial introduction, students who were only curious and were not interested in continuously logging in dropped off, while we could theorize that the remaining students who were inclined to use the app continued to use it.

Professor 1 class has 20 out of 40 students actively engage in the first week then drop to 10 out of 40 students the following weeks but does remain steady and is higher rate of activity in some areas. Professor 3 has 8 out 48 students in both classes it is offered for the first time and drops to 2 out of 48 students the following day. Professor 2 has 20 out of 64 students engaged the first time it is used and reduces to 8 out 64 the following week. Professor 4 has 15 out of 75 students engage. Professor 5 has 15 out of 50 students engaged. Professor 6 has 10 out of 50 students engaged in the app in both classes. It appears that the engagement drop off is less dramatic, when instructors actively remind students to interact with the app to post their emotion or ask a question and ask students to put their responses in the app, which was the case for Classes 1,4 , and 5.

To summarize how students use the app, it appears that students mainly continue to use it from class to class if the professors remind them to. The biggest proportion of participants is from the first class. Following the first class, we can expect a drop in participation numbers. As the app is used by subsequent classes, we find a consistent number of students are using the app. If the professors encourage usage of the app and integrate the usage of the app during class instruction, we can expect to see continued participation in the class. If the professors do not mention the app, do not remind students to use the app, or do not make any pointed connection between receiving feedback using the app during the class, then we can expect not to see any 
participation from students. This is because students will forget that they will need to login to the app or will not think it is necessary and will most likely not login if not asked to do so by their professors. Thus, instructors do need to regularly prompt and remind students to log into the app and post their emotions in the application.

"[I] have a hard time remembering to do it. But I also think that just being reminded to do it a bunch of times would also maybe be annoying... So maybe if they're like checkpoints." “...I would be less likely to do it unless I was prompted."

Figure 12. Class participation level in Emotion Thermometer app

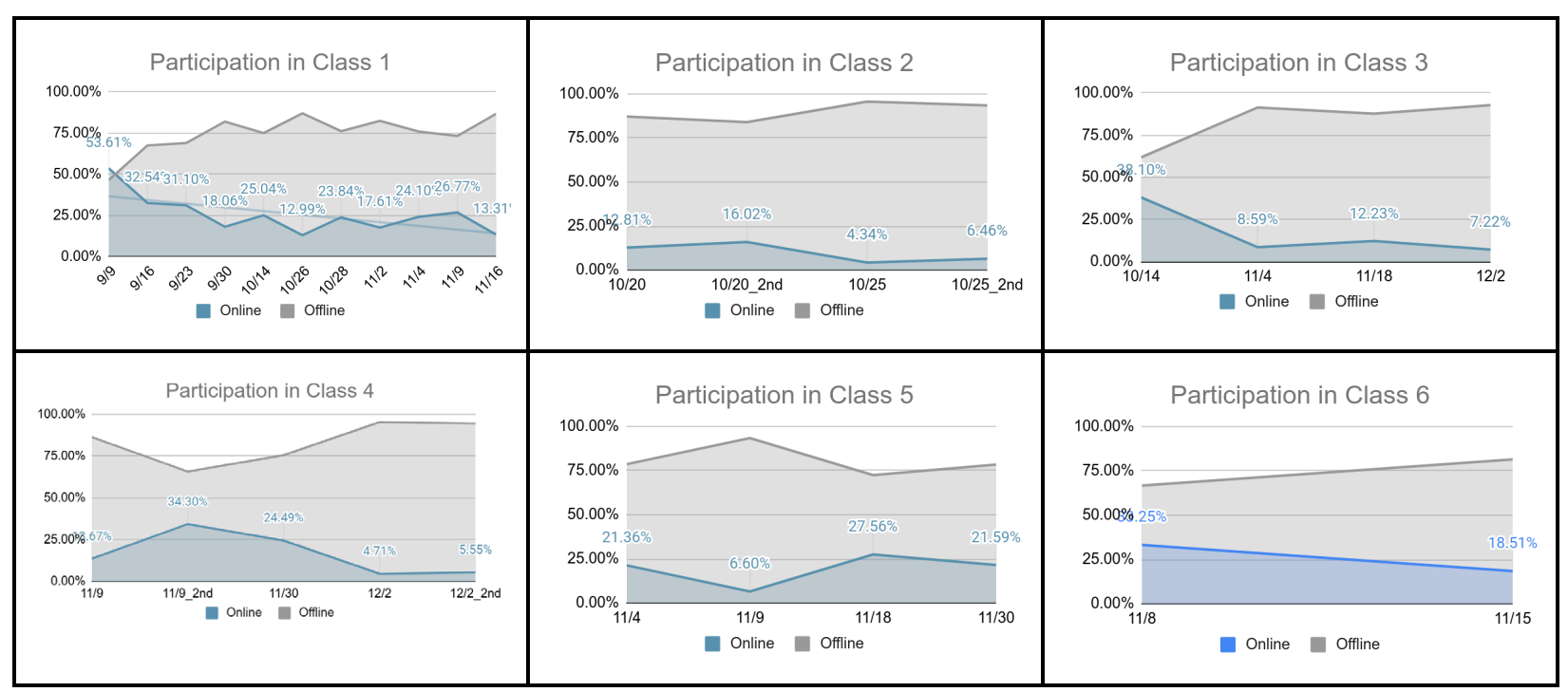

Figure 12. Class participation levels in percentages of those Online, students who logged in, and Offline, students who did not login into the Emotion Thermometer app but were registered for the class. 


\section{Figure 13. First vs Last class Online Participation}

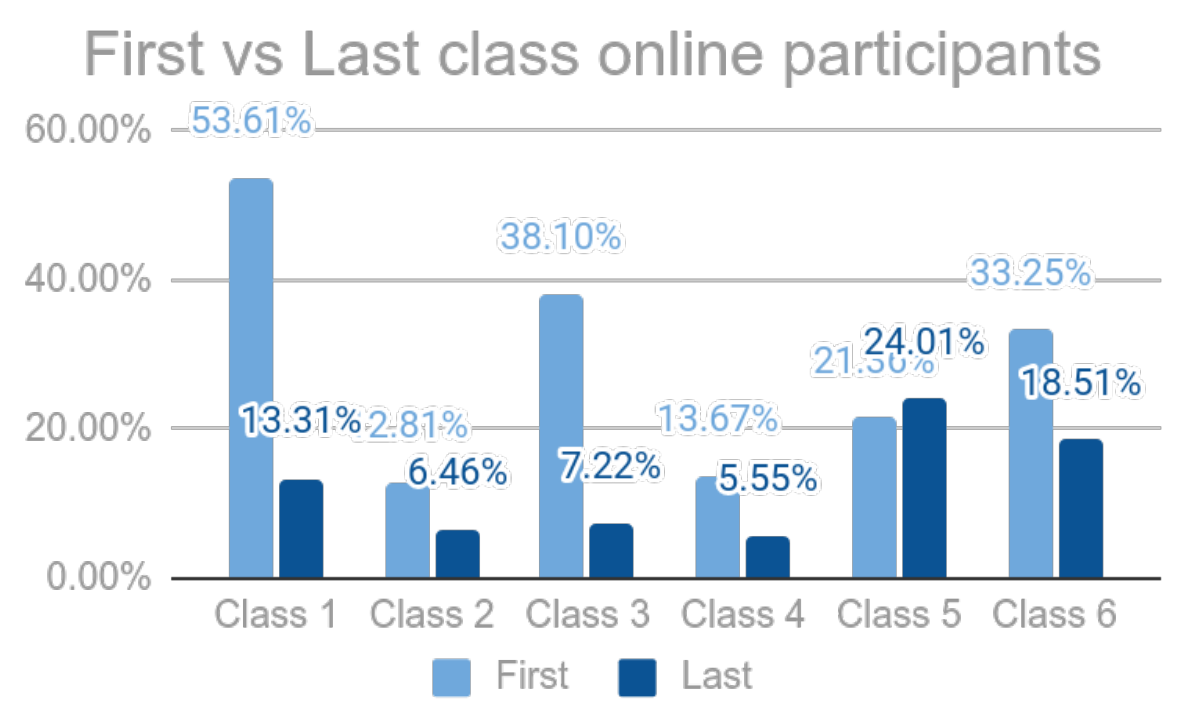

Figure 13. First and last lass participation levels compared in percentage to total emojis posted

Next, we will look at the types of emojis students choose in each class. In the following figures containing the bar chart, we have color-coded the emojis following the same mapping as we have followed in the Emoji Thermometer History page bar chart, see Table 1. 
Table 1. Emoji bar chart color mapping

\begin{tabular}{|c|c|c|}
\hline Chart Color & Emoji chosen & Label \\
\hline & 同 & I completely understand \\
\hline & $(-)$ & I think I'm getting it \\
\hline & $(9$ & Neutral \\
\hline & $\because$ & I think I'm lost \\
\hline & 织 & I completely don't understand \\
\hline & $\mathrm{n} / \mathrm{a}$ & Online not participated \\
\hline
\end{tabular}

Table 1. Provides the color mapping used throughout this thesis to indicate which emojis were chosen

In Figure 14, we can see how students choose varying types of emojis in their respective classes. We can see a pattern that most colors we see is yellow, which is the "Neutral" emoji. When students first log into the Emotion Thermometer app, and the web browser is in focus, the default radio button selected is "Neutral," shown in the chart as a yellow-colored bar. Every five minutes, the selected emoji radio button resets to "Neutral", or the yellow bar. This could be why we see a sizable majority of yellow bars in the chart, showing that the emojis chosen are "Neutral". Most likely, most students are not choosing an emoji at all but kept the page open throughout the class. Another possibility, could be that an emotion previously chosen, has reset to Neutral, and if they don't feel like their emotions have changed, or if they are not prompted by the professor, the chosen emoji by default will be yellow. 
Figure 14. Emoji bar chart color mapping

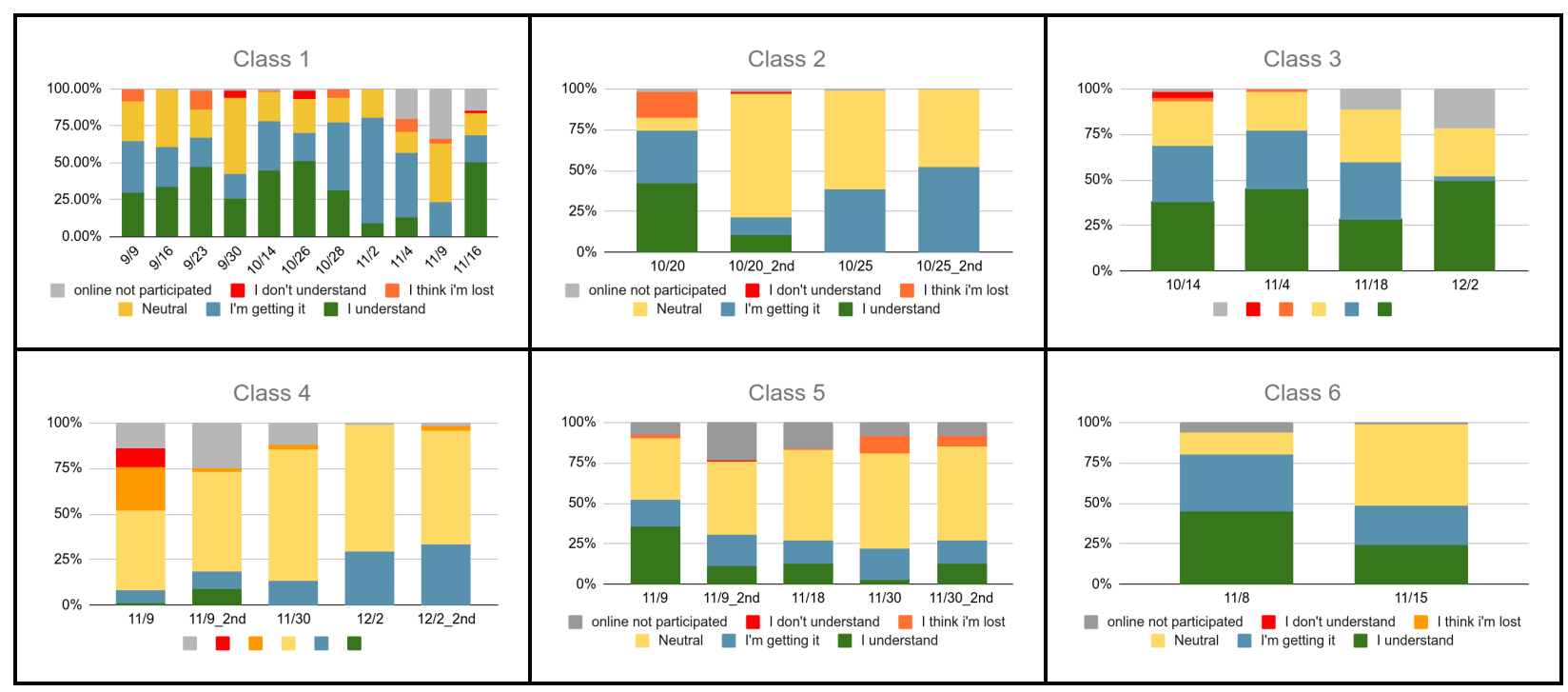

Figure 14. Display of all 6 classes with emojis chosen in each class the Emotion Thermometer app was used.

However, when we exclude neutral emojis and only look at either the positive emojis, i.e. "I completely understand" or "I think I'm getting it" or negative emojis, i.e. "I think I'm lost" or "I completely don't understand", of those emotions posted, we can see an overwhelming amount of the emojis actively chosen by students were the positive emojis. See Figure 15. 
Figure 15. Positive vs Negative Emotions posted

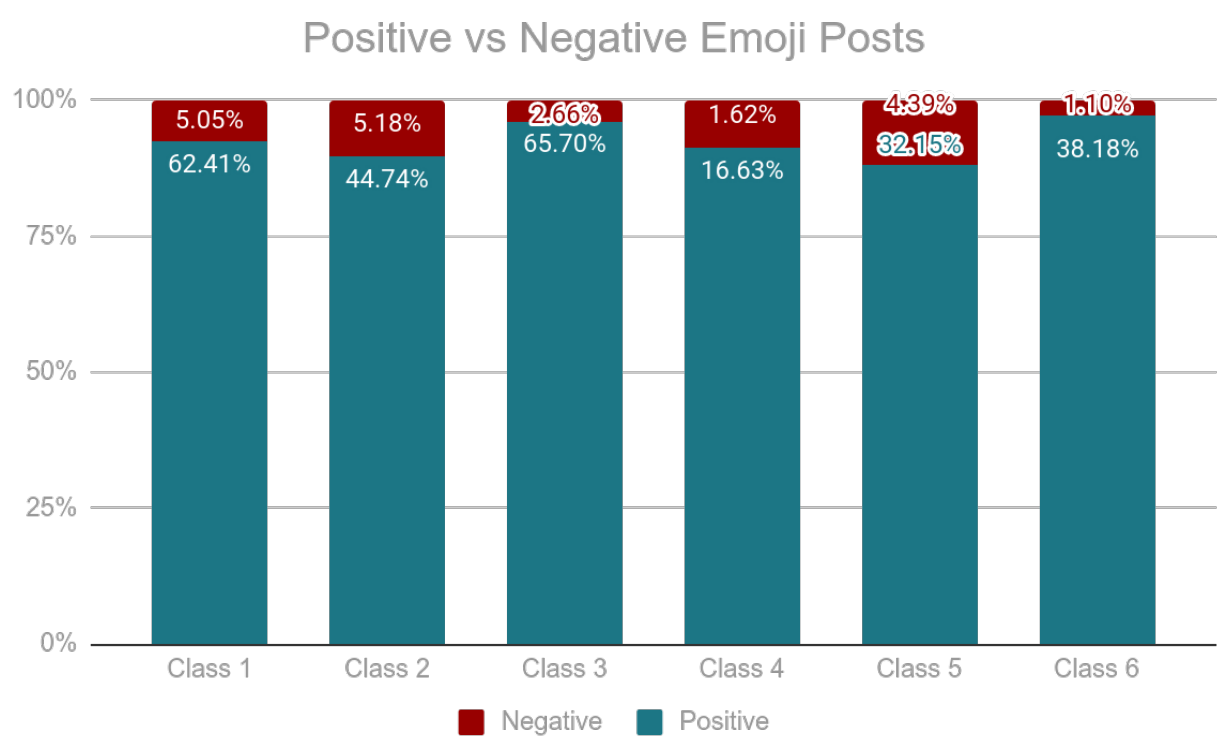

Figure 15. The positive and negative emotions are grouped together to easily conceptualize most emotions posted

One explanation could be because emoji icons are not sensitive enough to match emotions students are feeling. As noted by previous research, when users use emojis, they tend to choose more positive than negative (Harn 2017). That research had posited that the number of positive emojis available was larger than negative emojis, however, in this study, we have an equal amount of negative vs positive emotions. As part of our qualitative research, students interviewed felt that an emotion that would fall into the negative emotion category, did not perfectly fit with the emoji button choices: "I completely don't understand what's going on" or “I think I'm lost". Some students stated that when they don't understand, they would either not take any action, or they would prefer to describe their emotions/feedback in the free text field provided. 
Here's a quote from one of the students that describes this notion,

“And it I found [text-field] particularly useful in you know, expressing that I wasn't

understanding something. I like that it's(sic) not quite as blunt as just the X or the checkbox in zoom, which is what a lot of professors are asking us to use right now... But it's kind of hard to express like, gradations of not understanding. ... I tended to use it mostly for that. Like, I'm kind of clear."

In reading free text posted in the app, students use the freeform text box to send emotional support, to connect with their fellow students, and to connect with their professors. Positive comments are recorded. Out of 19 students who are online and participated, $\sim 4$ provided comments in the classes, we have 10 neutral comments 30 positive and 10 negative comments.

Positive comments are shown in sending positive encouragement to other students, or to send emotion not covered in the app; for example, in Professor 1 class, Student A says, "Let's get CONFIDENT". Students also use the app to post negative comments in a way to commiserate with their fellow students. For example, student in Professor 2 class, Student B says "tired" or student in Professor 5 class stated that "Projects are difficult". Students also use the text field to send to instructors that gives instructors feedback on what they need to understand. Neutral comments are when students are focusing on what they need and offering a solution to their problem. For example, students for Professor 2 says for example "I wish there were multiple clear full examples of each code required to be written so a student can verify all info has been added to get the code to work I find it hard like writing a [paper]" Another student for Professor 5 also sends very specific feedback "I think some concepts are still 5050 and confusing like arrays and $2 D$ arrays plus the functions as well like which functions to use with 
operator and how to use them so ya this is my feedback that I would like a bit more practice of programs". To better understand the comments submitted through the free text field under the Emoji radio button, we categorized the comments according as shown in Table 2. Most of the class provided a more neutral comment, such as "Hello", or "I'm here," in response to the professor asking students to specifically enter their emotions in the text field. Thus, we have categorized prompted comments as "Neutral." The remainder of comments can be categorized into categories that are General Positive comments, General Negative comments, Specific Positive comments, and Specific Negative comments. Examples of such comments and we categorized them are provided in Table 2.

Table 2. How Positive vs Negative Comments Are Categorized

\begin{tabular}{|c|c|}
\hline Category & $\begin{array}{l}\text { Examples of comments entered in the text } \\
\text { field for these category }\end{array}$ \\
\hline General Positive & $\begin{array}{l}\text { "Professor is amazing","I definitely get } \\
\text { it", "good explanation" }\end{array}$ \\
\hline Positive specific & $\begin{array}{l}\text { "I understand how an activation function } \\
\text { generally works", "generalization makes } \\
\text { sense to me" }\end{array}$ \\
\hline Neutral & "hole I am in", "Hi" \\
\hline Negative specific & $\begin{array}{l}\text { "I wish there were multiple clear full } \\
\text { examples of each code required...", } \\
\text { "I think some concepts are still } 5050 \text { and } \\
\text { confusing like arrays and 2D arrays ..." }\end{array}$ \\
\hline General Negative & "Tired", "I don't like list comprehension" \\
\hline
\end{tabular}

Table 2. How text-field comments are categorized into General Positive, Positive Specific, General Negative, Negative Specific, and Neutral. These are comments submitted through the text field on the Emotion Thermometer application. 
The following table, Table 3, provides a count of the categories of comments posted. We can see from the count of the emojis that Class 1, Class 5, and Class 4 have the most comments posted. When the professors of these classes were interviewed, the professors were the ones who either prompted students often to enter their comments in the field or referred to the comments submitted in the History page submitted during class.

Table 3. Positive vs Negative Comments posted

\begin{tabular}{|c|c|c|c|c|c|c|}
\hline & $\begin{array}{l}\text { Neutral: } \\
\text { In } \\
\text { response, } \\
\text { a hello }\end{array}$ & $\begin{array}{l}\text { General } \\
\text { positive } \\
\text { emotion: } \\
\text { professor is } \\
\text { amazing, } \\
\text { good } \\
\text { explanation }\end{array}$ & $\begin{array}{l}\text { Specific } \\
\text { positive } \\
\text { feedback: } \\
\text { easy, } \\
\text { understand }\end{array}$ & $\begin{array}{c}\text { General } \\
\text { negative: } \\
\text { overwhelmed, } \\
\text { tired, } \\
\text { difficult, } \\
\text { dislike }\end{array}$ & $\begin{array}{c}\text { Specific } \\
\text { negative } \\
\text { feedback: } \\
\text { need } \\
\text { examples } \\
\text { on arrays }\end{array}$ & $\begin{array}{c}\text { Total } \\
\text { comments }\end{array}$ \\
\hline $\begin{array}{c}\text { Class } \\
1\end{array}$ & 24 & 9 & 6 & 1 & 3 & 47 \\
\hline $\begin{array}{c}\text { Class } \\
2\end{array}$ & $\mathrm{n} / \mathrm{a}$ & 1 & 1 & 1 & 1 & 7 \\
\hline $\begin{array}{c}\text { Class } \\
3\end{array}$ & $\mathrm{n} / \mathrm{a}$ & 1 & $\mathrm{n} / \mathrm{a}$ & 2 & 1 & 4 \\
\hline $\begin{array}{c}\text { Class } \\
4\end{array}$ & $\mathrm{n} / \mathrm{a}$ & 2 & $\mathrm{n} /$ & 1 & 4 & 6 \\
\hline $\begin{array}{c}\text { Class } \\
5\end{array}$ & 14 & $\mathrm{n} / \mathrm{a}$ & 1 & 2 & 1 & 21 \\
\hline $\begin{array}{c}\text { Class } \\
6\end{array}$ & 4 & 1 & 1 & 1 & 1 & 7 \\
\hline
\end{tabular}


Table 3. Count of Positive and Negative comments posted through the text field in the Emotion Thermometer

If we look at the comments submitted on a percentage level, we can see that, in Table 4, that most comments were Neutral. This may be because comments we categorized as Neutral were the comments that students entered in the text field as a response to the professor. When unprompted, students enter comments in the text-field that are $25 \%$ of the time positive in nature, and $20.65 \%$ of the time negative/inquisitive in nature.

Table 4. Percentage table of positive, neutral, and negative comments

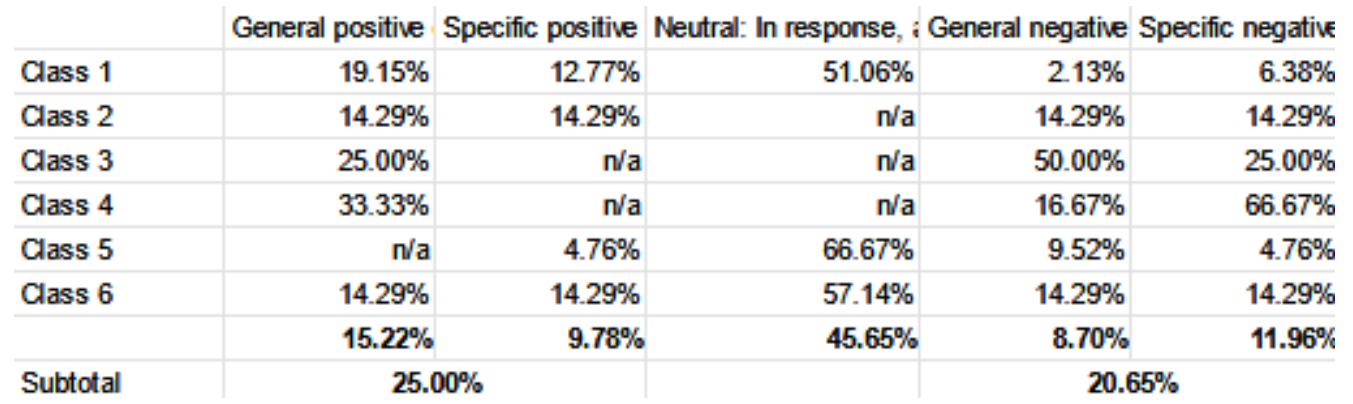

Table 4. Count of Positive, Neutral, and Negative comments posted through the text field in the Emotion Thermometer

In comparing the types of comments provided in each class, we can see that in Figure 15, classes 1, 5 and 6 appear to have more a mix between Positive, Neutral, and Negative comments, while classes 2, 3, and 4 have either Positive or Negative comments. One explanation for the difference between why classes 1,5 , and 6 have more Neutral-colored bars, is because students were prompted specifically to enter comments in the text field. Based on the qualitative student interviews. many students, $57.14 \%$ students mostly engage with the emoji application when prompted. Thus, we can conclude that most likely, in Classes 1,5, and 6 students were prompted and in Classes 2, 3, and 4 they were not prompted as often. 
Figure 15. Positive, Negative and Neutral Comments posted

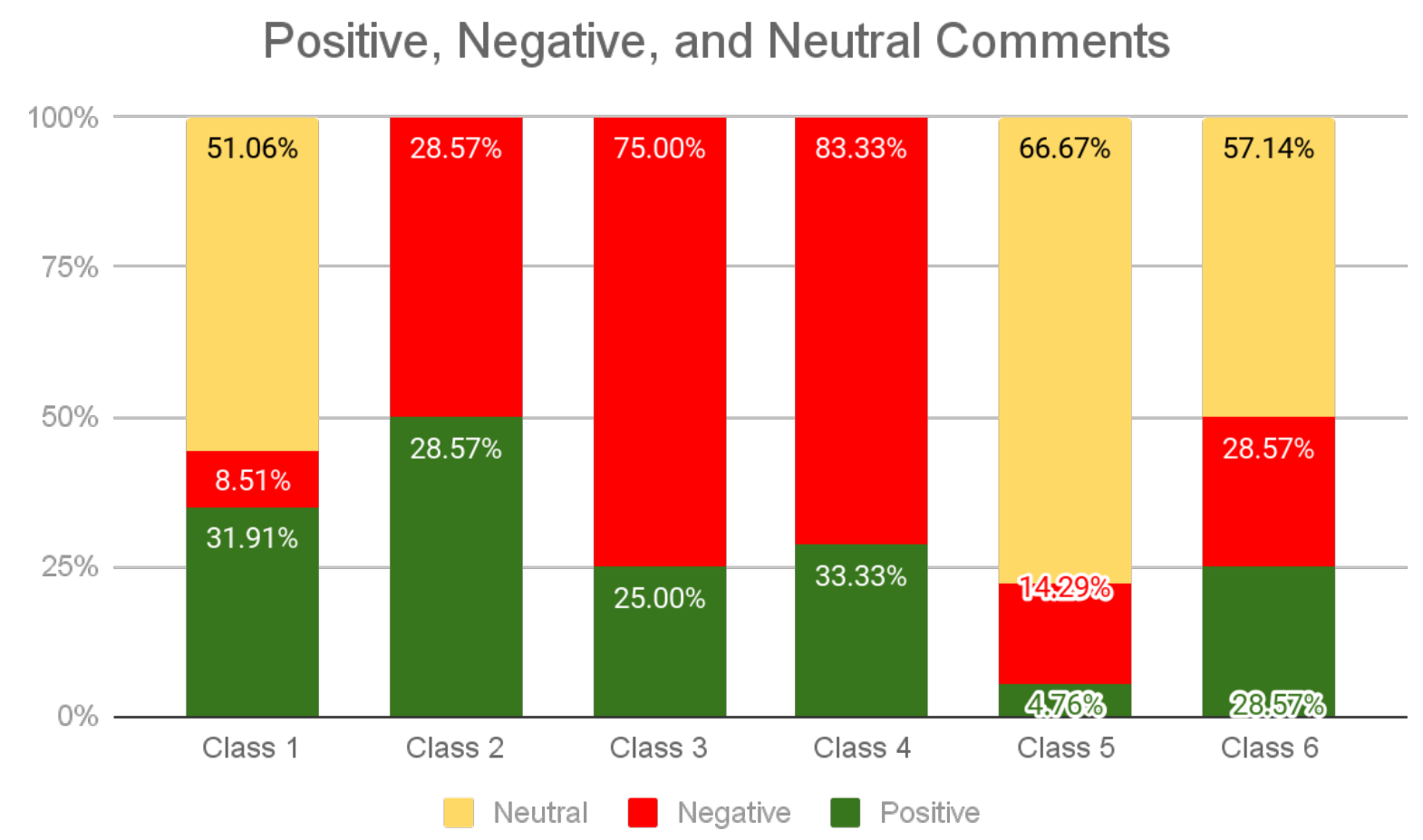

Figure 15. Percentage of Positive, Negative, and Neutral comments posted through the text field in the Emotion Thermometer

However, if we remove Neutral comments and only look at the percentages of Positive vs Negative comments, we can see a more even spread of the types of comments students will enter when not simply responding to a prompt. Please see Figure 16. 
Figure 16. Positive vs Negative Comments posted

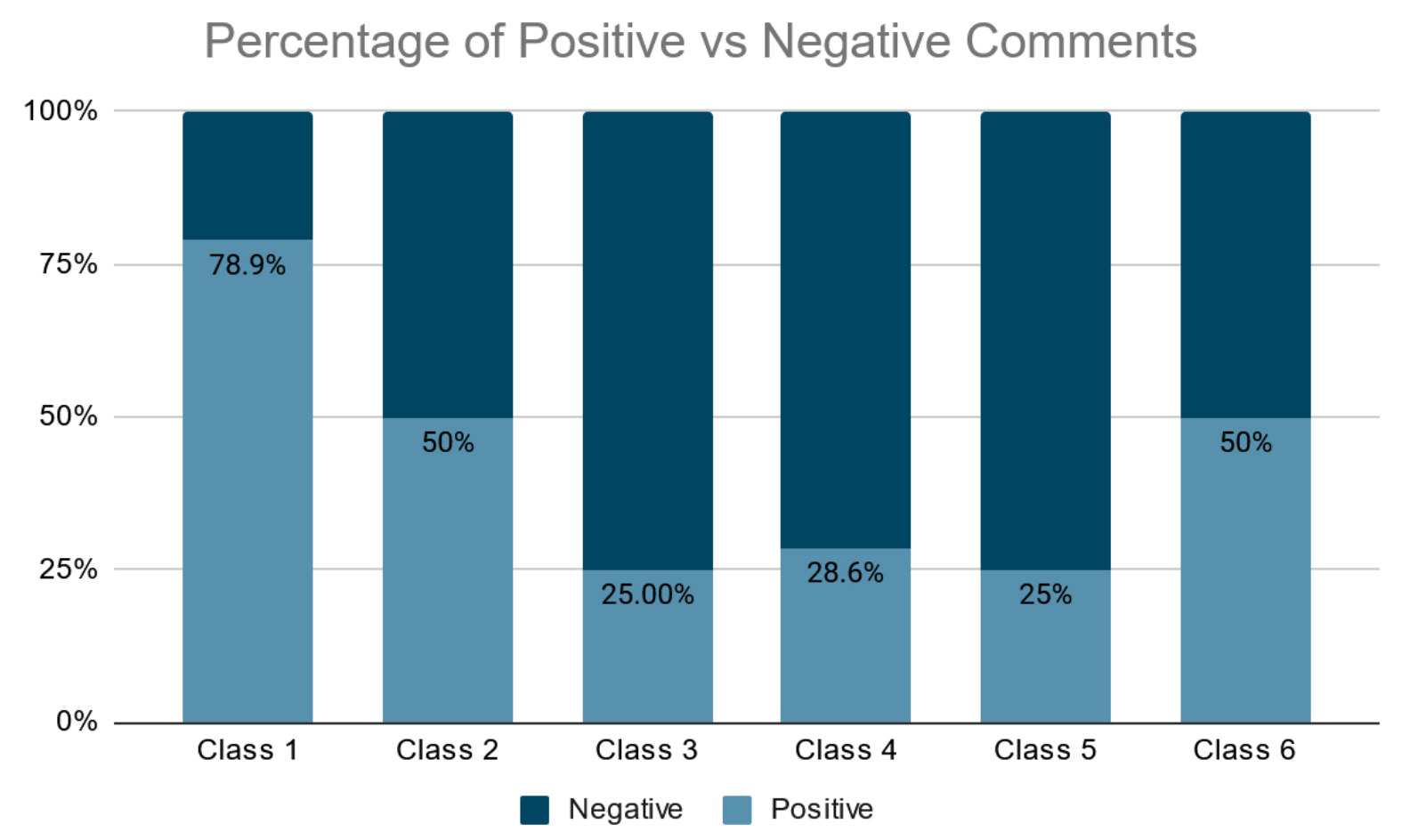

Figure 16. Percentage of Positive, Negative comments submitted through text field presented as percentage showing negative percentages are larger for classes that are less frequent and positive are higher for those more frequent users of the Emotion Thermometer

We can see that the largest percentage of positive comments are shown in Class 1 . Half of Class 2 and Class 6 had positive comments and in Classes 3, 4, and 5, positive comments make up $25-28.6 \%$ of the comments submitted in the text-field. Class 1 started using the Emotion Thermometer since September, while Class 3, 4, and 5, started in late October. If we look at the graph of how frequent the Emotion Thermometer is used, Figure 14, we can surmise that the more frequent the Emotion Thermometer is used comment submitted would be more 
positive. Both professors commented that they like the anonymous feature in the application, which they believe encourages students who are shy to post comments. To analyze this slice of data, we looked at were the number of students who entered comments as anonymous. In Figure 17, we can see that the proportion of classes where comments were anonymous were in Class 3 . Class 3 had used the Emotion Thermometer four times, like the number of times Emotion Thermometer app was used in Class 2. Seeing that the anonymous comments in Class 2 was less but had used the app the same amount of time, we can attribute the difference to how students felt their comments would be perceived in the class.

\section{Figure 17. Percentage of comments that were anonymous}

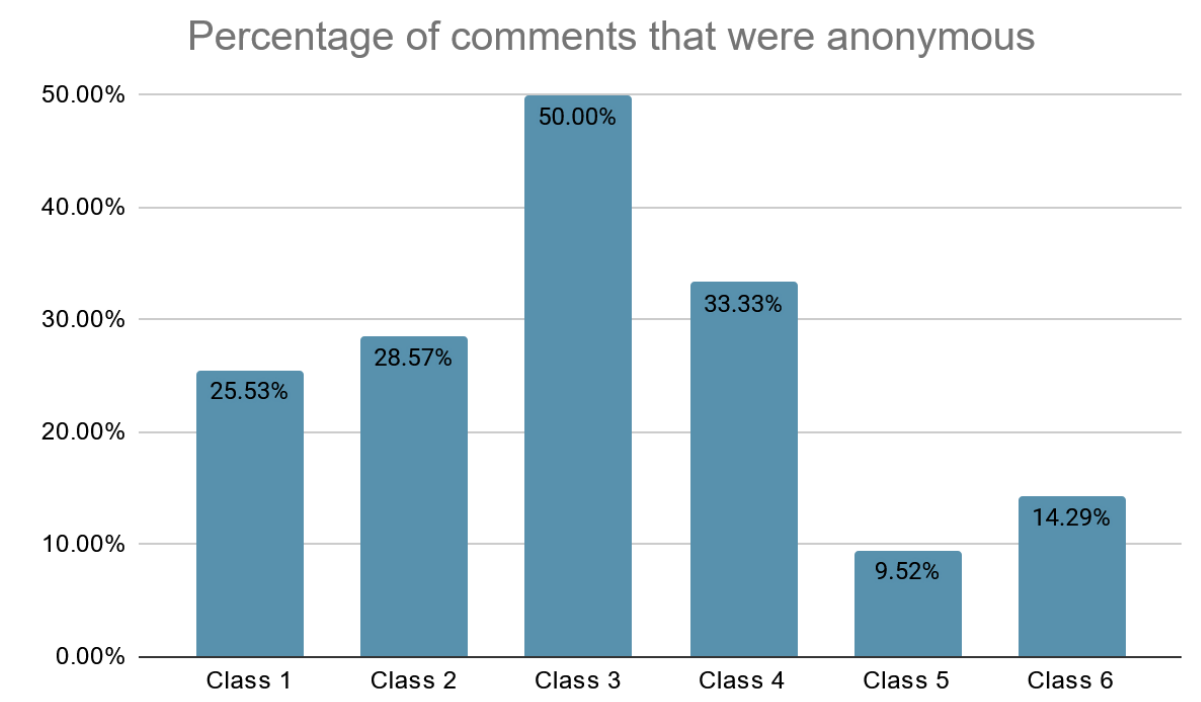


In terms of the usefulness of the text field, as well as the Anonymous button, it appears to have helped some students post specific feedback that they perhaps would not have otherwise communicated. In this way, the Emotion Thermometer has enabled students who have concerns to voice them earlier in the class.

After analyzing the quantitative results from the Emotion Thermometer app, we reached out to each class and asked students to reach out who would volunteer to provide feedback. We found 10 students who would volunteer and provide their comments one-on-one or as a pair, in a separate Zoom class link. Their answers were recorded on Zoom and transcribed using Otter.ai. Out of the 384 students enrolled in the class, we interviewed 10 students. Students voluntarily joined the researcher's private Zoom link, 4 students were interviewed individually, 6 students were interviewed in pairs. To answer the question: "Does using an emoji website to post emotions increase student satisfaction for SFSU students?”, we asked preliminary questions to lead up to that question. The first sub-question is "Will the use of an emoji app increase belonging and reduce feelings of isolation?". To identify further the definition of sense of belonging and feelings of isolation, we asked whether using the app changed students' level of communication with their peers and/or with their professors.

Students who felt that the app changed the way they communicate with professors noted it changed how their emotions are perceived and that it provided another option for the professors to receive feedback.

"I would say that our connection and understanding of our struggles and experiences are more let's see. Visible I guess, in a way?" 
"You know, some teachers, they're just like, you know, grades and then out of there, you know, but it's good to know that the teachers are also like, Okay, well, I hope you guys are also mentally okay, too. So that's nice to hear. “

The above feedback can be interpreted as students noting that their feedback seemed to matter more to professors. They made note that their comments seem more visible and that it was nice to know that the professors also care about their mental wellbeing, and not only their grades.

Students also felt the app changed the way they communicated with their peers. It can help encourage other peers that may be shier than they are to provide feedback or those who are not shy a non-intrusive way to providing feedback.

"I used it ... when we were in like a breakout room ... so it was helpful, because when, we would share out to help support ... our peers, we could use the emojis instead of ... interrupting or anything, it's more efficient, I would say."

"yeah. I still use the thermometer when I don't want to interrupt or anything."

Regarding the sense of belonging, students noted that while they don't feel it affected their sense of belonging it did make them feel as if they fit in more with the "flow" of the class.

"I'm not sure if it really affected my sense of belonging one way or another. And it did make me feel more comfortable asking questions without feeling like I was disrupting the flow of the class. So, in that way, it made me feel like I was fitting in to the flow of the class and not dominating the professor's attention."

Another student noted that the app helped them share their weakness as well as their strength. This student interpreted the app to encourage students to be vulnerable and thus will encourage them to continue in the course. 
Before asking the level of satisfaction question, we wanted to probe students for their feedback on how happy they were with the app's usability. We found several themes that kept coming up again and again. First, the app was difficult to use. Students had a hard time logging in and remembering their password and students had difficulty remembering when to use the app.

“...I probably wouldn't have used it as much just because ... there are separate login, separate credentials, have to remember what you're doing, you know. It's not centralized."

"But as a user to use this ... like the logging in every time can be like a little Oh, Iforgot my password ... it can be improved a little, ... make it easier for us to use it."

“... you have to be signed in to enter the class thing. Yeah. Sometimes. It's a hassle. Yeah. And ... it demotivates you from even like going into thing”

"I probably wouldn't have used it as much just because, um, because there is separate login, separate credentials, have to remember what you're doing, you know. It's not centralized." We should consider, for future iterations of the app, to remove the barrier to register and login to the application. Students found it cumbersome and have low motivation to login because of hurdles like forgetting their password, etc.

Secondly, there is not enough space on their digital device for another browser. Students often are using a browser already to following along with notes, an IDE when they're coding, and/or a Zoom link.

"I found it annoying to have to switch from the web browser to the zoom back to the web browser integration via zoom would have been good." 
Having another browser to open and toggle to and from is a hassle. Because of this digital space/real estate issue, students find having to input their emotions into the device while they are focusing on the topic sometimes distracting. This question is part of our sub-question, "Did using the app distract from learning?”

"I guess [it was distracting] because it wasn't integrated in zoom, you didn't just hit one button, and then it pops up in the right-hand corner and then it displays the results. And then you just hit it in like a widget and then it's done with anything that takes you out of the Zoom meeting is distraction."

On the flip side of the usability aspect, there were some benefits students noticed of having the app that it helped the professor remind themselves to slow down. And interestingly, a student also mentioned that having this tool, gave them less reason to say that they did not understand something.

"so that it did help in terms of just getting [the professor] to slow down where [they] needed to, but I don't think it really interrupted the flow of the class.

“it was beneficial to me because I didn't get to say I didn't understand something when otherwise I would."

Although there were some difficulties with the usability aspect of the app in terms of login, the digital real-estate, and the toggling back and forth between the app and the zoom. Overall, in terms of level of satisfaction, a student commented that there was a small bump in the level of satisfaction overall because the professors care about their relationships with the students.

"Again, it was it's really just nice knowing that the professor cares that we understand. ...So, you know, it does, it makes it feel a little more personal... in a world where we are very 
impersonal right now. And I think that, that went a long way for, you know, just establishing just a more trusting relationship with the professor."

There is some hesitation to satisfaction question because student had strong feedback about the usability changes needed of the application. But after weighing the pros and the cons, another commented on how the pros of inputting your emotions outweighed the cons of inconvenience.

"So, the idea of asking everyone in the middle of discussing a hard complex subject do you all understand it increases the sense of belonging, the ability to be vulnerable? So overall, on a social dynamic level, it probably does encourage people to be vulnerable, which then increases the likelihood that people might feel as if they would go on."

We found that being able to view the History chart was key to students feeling like they have a sense of belonging or part of the class. There was one professor who shared the History chart with their students. 3 out of the 10 students interviewed, who used the app knew where to find the History chart or was shared the History chart by their professor. Not seeing the History chart made students feel isolated, and students felt that they were mainly speaking only to the professors and not experiencing the camaraderie provided when they see the History chart.

Here are comments from students when asked whether using the app changed their sense of belonging in class from students who did not notice the History chart was an option.

"I don't really think so. Because I think it kind of just an individual thing for like, I always saw it as like a tool to help the professor rather than to help us well...."

"I think it definitely has more of an effect with the professor than the students. Because we're just clicking buttons on the last minute..., but most of the time is just like, sending our 
feedback with buttons to a professor. Right. And so, it was more of a connection with the professor."

Here are comments from students who we asked the same question about their sense of belonging and how it changed who did saw the History chart or was shared the chart by their professor.

"No, I think it kind of helped me feel like, there were other people that were also wondering the same stuff. Like in class, I would. I don't know if I would really be able to tell by looking around if people were viewed maybe kinda, but yeah, with the app, for sure."

"I'm feeling more integrated with each other is by sharing their feelings and weaknesses and strengths. ..."

"it was sometimes comforting to see that other people were not understanding something as well.

Additionally, all the students had suggestions on how we can use the app in the future. We noticed a theme from the suggestions which were for the app to be more built into the culture of the class, either by introducing it at the beginning, or perhaps integrating it as part of participation grade so that it is not voluntary, or as part of the class culture such as periodic reminders. And another student believed that there should be an alert when a certain emotion, for example, when students are not getting it, is selected.

"So, I feel like maybe finding a right balance ... making it part of the class culture ... Which I think would probably look like doing it from the very beginning. And maybe ... marked participation. I think if you make it optional unfortunately a lot of people just won't do it, or they'll forget..." 
“...there should be a notification when it reaches a certain emotion (such as when students get confused) for the Professor to be aware. I noticed that it's hard to see data and do lectures for the professors at the same time."

To answer our third research question, "Are professors were satisfied with the emoji website?", we asked sub-questions leading up to that main question with the following questions, "What are professors' perception and satisfaction on the online application?" and "Does increased communication increased this satisfaction for teachers."

Professors feel like the app does help act as an impetus to remind them to pause and ask students periodically as a tool they see can be part of their best practices for teaching and staying in touch with students.

"And I had certainly a few times where it like came in handy where I saw one or two students say I'm falling behind while I was teaching, and then I was like, Okay, this is a good reminder for me to take a break. And ask, ask the class, like, what they're confused about."

However, some professors feel that the logistics make it difficult to completely integrate the app into the class.

“Oh, well, no, I mean, to me, to me, I think it's just an overhead in what I want to focus on, okay, because during my teaching, I usually focus[ed]. “

"I have not asked them to respond in the middle of the class. Like I said, I'm already like juggling two, three things right then and there. So, I don't find it very helpful. ... it feels like more of a distraction when I'm trying to get them to like code on IntelliJ with me, rather than, like, ask them to open a browser and to something else. Yeah. So, I haven't I haven't reminded them that in the middle. But I have, I've reminded them to use it in the beginning and the end of the class." 
Here is a table that can help identify how different professors used the app throughout the class.

Table 5. How professors use the app

\begin{tabular}{|l|l|l|l|l|l|l|}
\hline & Prof 1 & Prof 2 & Prof 3 & Prof 4 & Prof 5 & Prof 6 \\
\hline Ask & Yes & $\mathrm{n} / \mathrm{a}^{*}$ & Yes & Yes & Yes & $\mathrm{n} / \mathrm{a}^{*}$ \\
login at the & & & & & & \\
start of \\
class
\end{tabular}

Table 5. How professors use the app in the class that affect student participation

Professor 7 introduced the Emotion Thermometer app, but for subsequent classes did not remind students to use the application. Furthermore, students in this class did not accounts created using their sfsu email but using a general account. Students were asked to go to the spreadsheet and get a general account assigned. A handful of students went to the spreadsheet to get the account, but none of the students went into the class link to use the app. Professor 7 believes that the app does not provide enough features to allow student and instructor to share 
emotion in two ways. Professor 7 believes that instructors should also be given an option to share their emotion to students.

In general, the professors like the application, and believe that it is useful. However, how much they use the application is tied to their desire to change their delivery during the semester or their philosophy on what will support student learning. Professors who do not believe they can modify the method during the semester did not find the app too helpful unless data can be compared from one semester to another. Three of the professors interviewed did find it helpful because it modified their lectures either by pausing, or by revisiting the topic in the next lecture, something they stated, as a best practice they wanted to remind themselves any way. The philosophy on whether the app can help support student learning, two of the four professors find that how students learn is their ability to find within themselves a way to learn and not necessarily an instructor checking whether a student understand the material in class. It may be that in the next release of the app to professor, it can be studied to see if there is a correlation between whether the fact that the application changes the communication level, and how student and professors communicate, whether that encourages students to achieve more success in their learning experience, or grades.

In terms of the satisfaction level with the app, two of the four professors interviewed mentioned that it may have gained more usage if it was being invested in more and intended to introduce it as the means of communicating at the beginning of the class and suggest it would be even better, if the application is more integrated into the main web conference application, i.e., Zoom. 
"I think I think the, like, major challenge of this app, in general is that it's like a separate thing. It's a separate webpage. “

"And I had certainly a few times where it like came in handy where I saw one or two students say I'm falling behind while I was teaching, and then I was like, Okay, this is a good reminder for me to take a break. And ask, ask the class, like, what they're confused about."

However, one of the features they like most about the application is that it allowed for anonymous comments, which Zoom currently doesn't provide. And in terms of the convenience factor, the application has played the role of a low-effort survey.

"Or like, oh, somebody says they're falling behind, and that might prompt them. But I didn't, I certainly didn't specifically, say like, Okay, everybody fills it out, which could be a good thing to do. It's a nice little, low, low effort survey. “"

Also, another feature professor used is the History chart. This data allowed them to identify the topic discussed at the time and come back the next class with revising that topic.

"I was very happy seeing the data because this one place where the student says I had good explanation (sic)...showing them an example just to go slow on the content ... And I know, that is the part that is exactly when I began explaining one of the concepts that some of the students said, were confusing in the earlier class ... So that's the kind of mapping that I'm trying to do and try to understand, you know, what needs to be done in the class"

From the professor's comments above, we can deduce that the professor is looking at both the History chart as well as the text-field. 92 total comments from the text-field were submitted, out of the $18.15 \%$ of all that were enrolled and were online provided real-time feedback to the instructor. These numbers show that the text-field is useful, and we should 
continue to use the text-field to provide students an opportunity to provide more specific comments in class.

Lastly, despite the applications hurdles such as the login/registration page and the students'/professors' digital real estate, overall, students and professor did appreciate the app and students expressed that they felt that it "bumped" their satisfaction level. Students mentioned that they experience a satisfaction with their professor. And even the student who were already comfortable with the camera or speaking up, these students were also appreciative of the additional way of communication that the Emotion Thermometer app provides.

"I think I probably bumped it up a little bit. Again, it was it's just nice knowing that the professor cares that we understand. So, you know, it does, it makes it feel a little more personal. in a, in a world where we are very impersonal right now. And I think that, that went a long way for, you know, just establishing just a more trusting relationship with the professor."

"So, I feel like I generally rely on [having my camera on]. But I totally get that everybody wants to have their camera off, which is fine. So, I think that learning is best when you just have as many, like different ways of accomplishing it as possible. So, I feel like if that, I think that could be something that's useful for other people who, who prefer to not have their camera on in order to like, achieve the same result."

Some students appreciate that the professor has made the Emotion Thermometer app available to help all students feel less awkward in class

"I'm also an Army vet. So, you know, we're, I feel like us, we're more prompted to, to open our mouths and ask a question. ... There is not a lot of people who do who do talk in our class, it's very quiet. So, I feel like there is a lot of shyness there. So, as another student listening, 
I know I stay quiet a lot. I just open my mouth when I have a question. Yeah. But usually, the class is very quiet."

\section{Conclusion and Future Work}

From the above results, we can conclude that the Emotion Thermometer app did change how students and professors communicated with each other. Students noted that they felt their emotions were more visible and felt better about sending communication at any point without hesitating because they did not want to interrupt the flow of the class. And professors noted that it also changed how they paused the material. Having the Emotion Thermometer app acted as a proxy, at the very least a reminder, to pause and check with students on whether the pace is appropriate. Areas for improvement in participation include addressing the main reasons why students won't use the app, which are removing login/registration as well as incorporating the Emotion Thermometer app in the Zoom app. We previously created the login/registration to help students feel their data is more secure, but a simple link, judging from comments in the interviews, seem to imply anonymity sufficiently.

In terms of student satisfaction, we did see from interview comments that 3 out of 10 students student stated that they feel better about the professor because the professor is using the Emotion Thermometer which insinuates that they care about the student well-being. In terms of professor's satisfaction, it appears that professors are also inclined to use it again. 3 out of the 4 professors interviewed expressed interested in using the following semester and using it earlier and more integrated in their classes. 
Limitations of the study may include that using the application was voluntary. It is used by professors who were already interested in receiving student feedback. And once the professors use the app in class, it is also voluntary for students to login. For students who did login and submit their comments, from the 10 students we interviewed, it appeared that 3 out of the 7 students interviewed were already comfortable with their level of communication with their professors. These students made suggestions on how the app can be used more, i.e., how to gain more participants, by integrating the app into the "culture" of the class. For example, by introducing the app at the beginning of the class, tying it to a grade, or placing reminders in the application to remind either students or professors to pause.

There were some suggestions provided to the researcher from student and professor interviews in response to the limited digital real estate and the low participation rates. Some suggested that the app can be downloaded as a native mobile app, others have suggested that the students browser can be minimized to just the radio buttons for example. Some professors and students have also mentioned that periodic reminders can be helpful for both professors and students, but there was ambivalence there in determining what interval would be relevant. One idea could be to provide users with the ability to identify the interval time-frame, controlled by the professor. Some students and professors also mentioned that the Emotion Thermometer app can be useful when the classrooms move offline, or hybrid. There appears to be acceptance to keeping the Emotion Thermometer app on students laptops.

To summarize, while it can use some improvements in how it was delivered by professors to students and how it is integrated into the classrooms, or class conference application, the Emotion Thermometer app did change how students communicated with the 
professors and both parties found it useful. We encourage the app to continue to be improved and be introduced in more classes earlier in the semester to see whether we can further encourage student-professor interaction online and offline. A handful of the students and professors we interviewed did express that the application can be extended and have less of a digital real estate problem if it were used in a physical classroom. Furthermore, we can collect more data to identify whether increasing communication, improves sense of belonging, and improves learning outcomes. By using the app to collect more data especially in the Covid-19 pandemic environment we can study how we can create a less impersonal environment we are in, so we can help both students and professors feel that they are in a protective learning space and it is part of the learning experience to be vulnerable. 


\section{Works Cited}

DeAndrea, D.C., et al., Serious social media: On the use of social media for improving students' adjustment to college. Internet and Higher Education (2011). doi:10.1016/j.iheduc.2011.05.009

Emma R. Wester, Lisa L. Walsh, Sandra Arango-Caro, and Kristine L. Callis-Duehl, Student Engagement Declines in STEM Undergraduates during COVID-19-Driven Remote Learning. Donald Danforth Plant Science Center, St. Louis, Missouri, USA 63132, St. Louis University, St. Louis, Missouri, USA 63103. Journal of Microbiology \& Biology Education https://doi.org/10.1128/jmbe.v22i1.2385

Farshad, Raya. "Emotion Thermometer app." San Francisco State University, Master's Project Report. 2020.

Harn, Ren-Whei. “The Visual Language of Emojis: A Study on College Students' Social Support Communication in Online Social Networks.” University of Kansas. April 28, 2017. https://kuscholarworks.ku.edu/handle/1808/26036

Kaye, Linda K., Stephanie A. Malone, Helen J. Wall, “Emojis: Insights, Affordances, and Possibilities for Psychological Science," Trends in Cognitive Sciences, Volume 21, Issue 2, 2017, Pages 66-68, ISSN 1364- 6613, https://doi.org/10.1016/j.tics.2016.10.007 .

LeBlanc, Christina A., "First-Year Computer Science Students: Pathways and Perceptions in Introductory Computer Science Courses" (2020). Electronic Theses and Dissertations. 3160. https://digitalcommons.library.umaine.edu/etd/3160 
O'Brian, Jessica (2020) "The Relationship Between Self-Reported Emotional Intelligence and Emoji Identification Accuracy in College Students," Ursidae: The Undergraduate Research Journal at the University of Northern Colorado: Vol. 9 : No. 1 , Article 1. Available at: https://digscholarship.unco.edu/urj/vol9/iss1/1

Pourmand, A., Quan, T., Amini, S. B., \& Sikka, N. Can Emoji’s assess patients' mood and emotion in the emergency department? An emoji-based study. (2020) The American Journal of Emergency Medicine, Volume 38, Issue 4, 2020, Pages 842-843, ISSN 0735 6757, https://doi.org/10.1016/j.ajem.2019.09.008

Reem Al Zou'bi, Fathi Shamma (2021). Assessing Instructors' Usage of Emojis in Distance Education during the COVID-19 Pandemic. Cypriot Journal of Educational Science. 16(1), 201-219. https://doi.org/10.18844/cjes.v16i1.5520

Simpson-Scarborough (2021, March). The Impact of COVID-19 on Higher Education. Higher Ed and COVID-19 national student survey. https://impact.simpsonscarborough.com/covid19/

Simpson-Scarborough (2021, March). The Impact of COVID-19 on Higher Education. Higher Ed and Trujillo G, Tanner KD. 2014. Considering the role of affect in learning: monitoring students' self-efficacy, sense of belonging, and science identity. CBE Life Sci Educ 13:6-15. https://doi.org/10.1187/cbe.13-12-0241

Son, Changwon et al. "Effects of COVID-19 on College Students' Mental Health in the United States: Interview Survey Study.” Journal of medical Internet research vol. 22,9 e21279. 3 Sep. 2020, doi:10.2196/21279. https://www.ncbi.nlm.nih.gov/pmc/articles/PMC7473764/ 
York, Dustin (2014) "Professional Development: The Use of Nonverbal Communication During Class Lecture," Journal of Educational Leadership in Action: Vol. 2 : Iss. 2 , Article 6. Available at: https://digitalcommons.lindenwood.edu/ela/vol2/iss2/6 